\title{
Tidal Energy Round Robin Tests: A Comparison of Flow Measurements and Turbine Loading
}

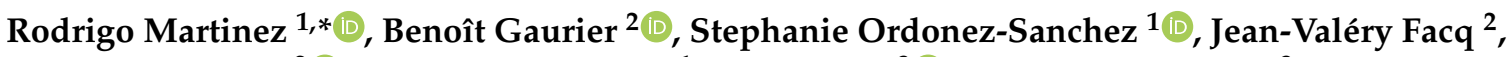 \\ Gregory Germain ${ }^{2}{ }^{\circledR}$, Cameron Johnstone ${ }^{1}$, Ivan Santic ${ }^{3}{ }^{\oplus}$, Francesco Salvatore ${ }^{3}$, Thomas Davey ${ }^{4}(\mathbb{D}$, \\ Chris Old ${ }^{5}$ (i) and Brian G. Sellar ${ }^{5}$ (i)
}

1 ESRU, Department of Mechanical \& Aerospace Engineering, University of Strathclyde, James Weir Building, Montrose Street, Glasgow G1 1XJ, UK; s.ordonez@strath.ac.uk (S.O.-S.); cameron.johnstone@strath.ac.uk (C.J.)

2 Marine Structures Laboratory, IFREMER, 150 Quai Gambetta, 62200 Boulogne-Sur-Mer, France; bgaurier@ifremer.fr (B.G.); jvfacq@ifremer.fr (J.-V.F.); ggermain@ifremer.fr (G.G.)

3 National Research Council, Marine Technology Research Institute, CNR-INM, Via di Vallerano 139, 00128 Rome, Italy; ivan.santic@insean.cnr.it (I.S.); francesco.salvatore@cnr.it (F.S.)

4 School of Engineering, Institute for Energy Systems, FloWave Ocean Energy Research Facility, The University of Edinburgh, Max Born Crescent, Edinburgh EH9 3BF, UK; tom.davey@flowave.ed.ac.uk

5 School of Engineering, Institute for Energy Systems, The University of Edinburgh, Max Born Crescent, Edinburgh EH9 3BF, UK; C.Old@ed.ac.uk (C.O.); Brian.Sellar@ed.ac.uk (B.G.S.)

* Correspondence: r.martinez@strath.ac.uk

check for updates

Citation: Martinez, R.; Gaurier, B.; Ordonez-Sanchez, S.; Facq, J.-V.;

Germain, G.; Johnstone, C.; Santic, I.; Salvatore, F.; Davey, T.; Old, C.; et al. Tidal Energy Round Robin Tests: A Comparison of Flow Measurements and Turbine Loading. J. Mar. Sci. Eng. 2021, 9, 425. https://doi.org/

$10.3390 /$ jmse 9040425

Academic Editor: Manhar R. Dhanak

Received: 3 March 2021

Accepted: 12 April 2021

Published: 14 April 2021

Publisher's Note: MDPI stays neutral with regard to jurisdictional claims in published maps and institutional affiliations.

Copyright: (c) 2021 by the authors. Licensee MDPI, Basel, Switzerland. This article is an open access article distributed under the terms and conditions of the Creative Commons Attribution (CC BY) license (https:// creativecommons.org/licenses/by/ $4.0 /)$.

\begin{abstract}
A Round Robin Tests program is being undertaken within the EC MaRINET2 initiative. This programme studies the used facility influence can have on the performance evaluation of a horizontal axis tidal turbine prototype when it is operated under wave and current conditions. In this paper, we present the design of experiments that is used throughout the work programme and the results related to the flow characterisation obtained at the IFREMER wave and current circulating tank, the CNR-INM wave towing tank and the ocean research facility FLOWAVE. These facilities have been identified to provide adequate geometric conditions to accommodate a $0.724 \mathrm{~m}$ diameter turbine operating at flow velocities of 0.8 and $1.0 \mathrm{~m} / \mathrm{s}$. The set-up is replicated in each of the facilities with exemption of the amount of flow measuring instruments. Intrinsic differences in creating wave and currents between facilities are found. Flow velocities are up to $10 \%$ higher than the nominal values and wave amplitudes higher than the target values by up to a factor of 2 . These discrepancies are related to the flow and wave generation methods used at each facility. When the flow velocity is measured besides the rotor, the velocity presents an increase of $8 \%$ compared to the upstream measurements.
\end{abstract}

Keywords: marine energy; wave and current interactions; Round Robin tests; flow measurements; horizontal axis tidal turbine; uncertainty analysis

\section{Introduction}

The development of new technologies relies heavily on prototype testing activities. These tests are usually carried out in laboratories that are able to provide similar conditions to the real environment in controllable scenarios where certain parameters can be adjusted as required. In the case of ocean energy conversion research, the test environment may influence measurements related to power capture or loading, which, in consequence, influence the design of the device.

To identify the influence of the test environment on the device's performance, interlaboratory tests can be undertaken using the same testing device and subjected to the same testing conditions. These experiments are a common practice and are referred as Round Robin Tests (RRTs). For that programme, the exact same $0.724 \mathrm{~m}$ diameter horizontal axis tidal turbine (HATT) is tested in two tow and two flume tanks. Small discrepancies 
between average values of power and thrust are obtained giving confidence in the highquality operation under current-only conditions of the four research infrastructures used at that time. Moreover, an insightful conclusion drawn from the work of [1] indicated that, even at low blockage ratio conditions of about $5 \%$, the turbine performance within operation ranges between peak power and free-wheeling are impacted. To minimise the influence of blockage, correction algorithms are implemented based on the work from [2].

Other attempts to identify turbine model practicalities using RRTs have been reported in [3,4]. Murray et al. [3] compared the performance of a HATT in a flume and a tow tank using two types of blade materials: composites and solid aluminium blades. Small variations between power and thrust are obtained which are merely related to the turbulence levels developed in the flume. Allmark et al. [4] compared the effects of measuring the device performance using motor current measurements instead of commonly employed torque and thrust transducers. It is found that substantial efforts to characterise the motor need to be undertaken to minimise uncertainties between measurements. Both campaigns as well as that reported in [1] only considered the use of current-only conditions.

Efforts from the scientific community to drive forward the development of tidal stream technology include the estimation of performance and structural loading when these devices are subjected to diverse wave and current conditions e.g., [5-12]. As observed in Table 1, most of these studies have also been undertaken in diverse facilities under different conditions. It is also clear that there is a progression in this line of research, moving from the more controllable aspects; for instance, the use of regular waves to more complex situations including irregular waves and directionality.

Table 1. Wave-current interaction experiments undertaken with three-bladed HATTs.

\begin{tabular}{|c|c|c|c|}
\hline Author & Facility & Rotor $\varnothing[\mathrm{m}]$ & Wave Characteristics \\
\hline Barltrop et al., 2007 [5] & Towing tank. Strathclyde University & 0.4 & Collinear regular waves \\
\hline Gaurier et al., 2013 [6] & Flume tank. IFREMER & 0.9 & Collinear regular waves \\
\hline Galloway et al., 2014 [7] & Towing tank. Southampton University & 0.8 & Collinear regular waves \\
\hline Henriques et al., 2015 [8] & Flume tank. University of Liverpool & 0.5 & Collinear regular waves \\
\hline Martinez et al., 2018 [9] & Flume tank. FLOWAVE & 1.2 & Multi-directional regular waves \\
\hline Ordonez-Sanchez et al., 2019 [10] & Towing tank. CNR-INM & 0.9 & Collinear regular and irregular waves \\
\hline Draycott et al., 2019 [11] & Flume tank. FLOWAVE & 1.2 & Collinear and opposing irregular waves \\
\hline Draycott et al., 2019 [12] & Flume tank. FLOWAVE & 1.2 & Focused wave groups \\
\hline Porter et al., 2019 [13] & Flume tank. IFREMER & 0.9 & $\begin{array}{l}\text { Collinear regular waves. } \\
\text { Passively adaptive composite blades }\end{array}$ \\
\hline Martinez et al., 2020 [14] & Flume tank. IFREMER & 0.9 & Collinear regular and irregular waves \\
\hline
\end{tabular}

The research developed by the authors in Table 1, although crucial for the development of marine devices, may be difficult to relate due to the number of variables related to device geometry, facility, flow conditions, etc. Thus, the aim of this work is to evaluate the methodology implemented to assess the performance of a generic tidal stream turbine and the flow characteristics at each facility regarding the quality of the flows and waves generated. This paper complements the work done by [15], where the authors studied in detail the performance of the turbine through non-dimensional analyses using a technique to establish the input flow characteristics and blockage effects.

\section{Design of Experiment}

The purpose of this investigation is to identify the potential effects that research infrastructures may have on the evaluation of small scale tidal stream turbines performance. To meet this objective, three controlled facilities (Table 2) are selected to undertake this evaluation. 
Table 2. Main characteristics of the controlled testing facilities.

\begin{tabular}{cccc}
\hline Laboratory & IFREMER & CNR-INM & FLOWAVE \\
\hline Type of tank & flume & towing & flume \\
Length [m] & 18 & 220 & 10 \\
Width $\times$ Depth [m] & $4 \times 2$ & $9 \times 3.5$ & $10 \times 2$ \\
Speed range [m/s] & 0.1 to 2.2 & 0.1 to 10 & 0.1 to 1.6 \\
Turbulence int. [\%] & 1.5 to 15 & - & 5 to 11 \\
\hline
\end{tabular}

Initially, the design of the experiments reported here attempts to follow the experimental process described in the EquiMar protocol [16] adapted from the ITTC Procedure 7.5-02-02-01 [17,18]. To describe the methodology that is used for the entire RRT programme, this paper focuses on the design of the experiments, the initial findings related to the quality of the flow and waves generated and the turbine performance obtained at three research facilities: the circulating flume tank of IFREMER [19], the tow tank of CNR-INM [20] and FLOWAVE TT [21]. Finally, an uncertainty analysis is presented to understand any deficiencies with the adopted methodology.

\subsection{Model Specifications and Installation}

The desired parameters required for the evaluation of the RRT are, mainly, flow characterisation of the facilities used and the loading and performance of the model tidal turbine. To meet the latter criteria, a 1:20 scale, three-bladed horizontal axis turbine model developed by IFREMER is used in this campaign [1]. The turbine is $0.724 \mathrm{~m}$ in diameter $(D)$ and is equipped with three blades which are $307 \mathrm{~mm}$ long. This is representative of a $\simeq 15 \mathrm{~m}$ diameter turbine at full scale. The blade design is based on a NACA 63-418 profile. A mounting flange to adapt the supporting stanchion or tower is located $594 \mathrm{~mm}(0.82 D)$ from the rotor plane (Figure 1). The turbine is rated at TSR $=4$ and is designed to operate for a maximum flow velocity of $1.2 \mathrm{~m} / \mathrm{s}$.

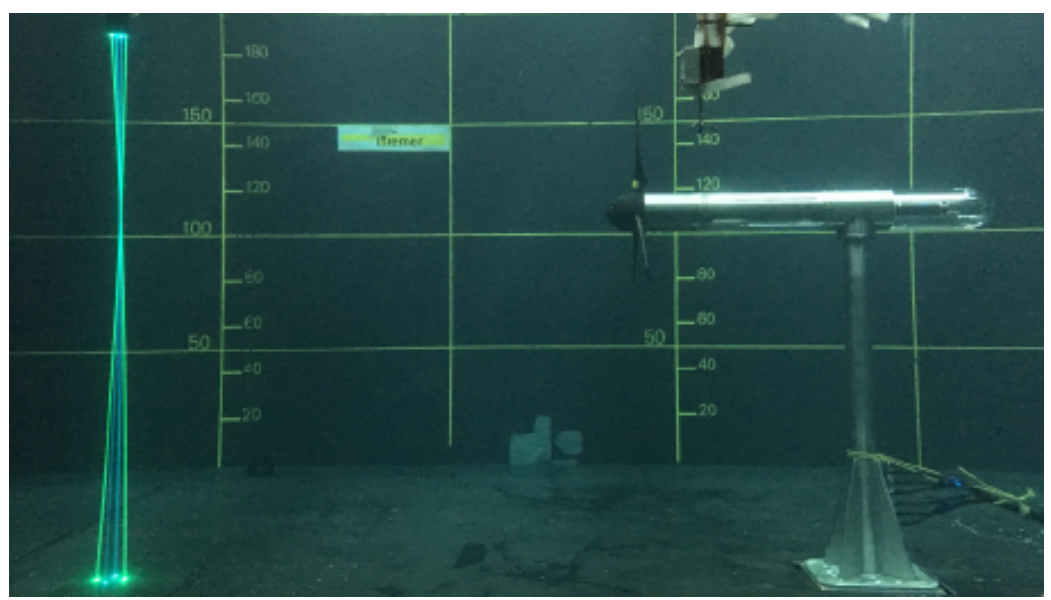

Figure 1. Side view of the three-bladed instrumented turbine in the wave and current flume tank of IFREMER.

The turbine is fixed to a moving carriage on the towing tank (mounted from the top) and on a customised mounting frame in the flume tanks at IFREMER and FLOWAVE (mounted from the bottom). The turbine is kept at a constant depth of $1.0 \mathrm{~m}$, to keep it in mid-water conditions according to the depth specifications of most of the tanks used in the RRTs. For a detailed description of the turbine setup, see [15]. 


\subsection{Measurement Systems}

\subsubsection{Turbine Instrumentation}

The generic turbine model is equipped with a dedicated load cell measuring the torque $Q$ and thrust $T$ applied on the main rotation axis of the rotor. This waterproof transducer (Figure 2) is positioned upstream of the rotor seals to prevent parasitic friction effects. The torque and thrust transducer are custom made by the French company SIXAXES [22] in partnership with IFREMER. The measurement ranges of each of the instruments are summarised in Table 3.

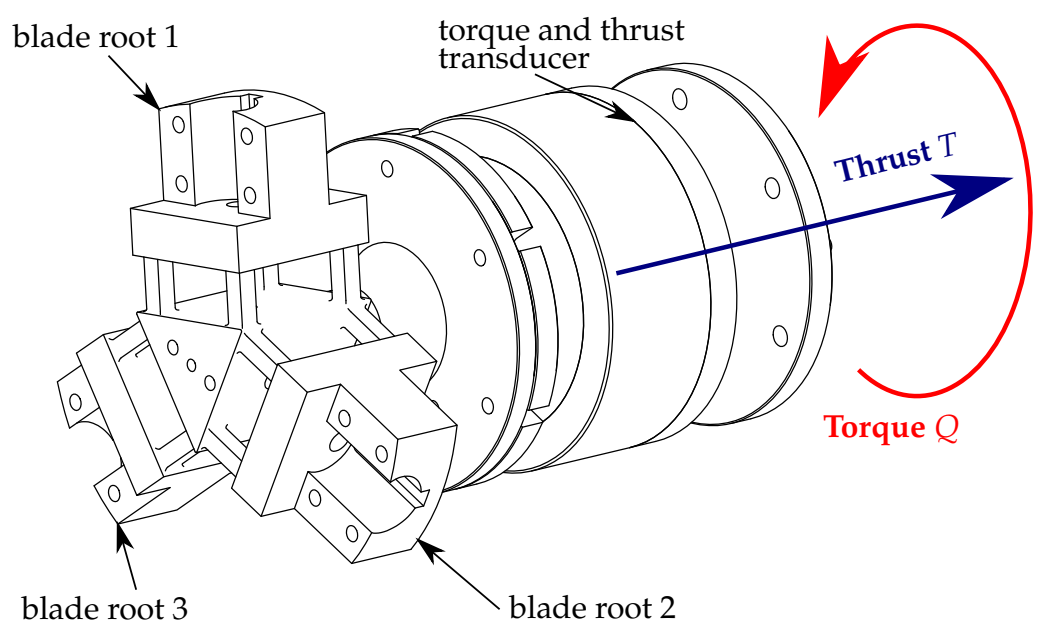

Figure 2. The torque and thrust transducer.

The shielded cables coming from the transducer are routed through a slip-ring enabling the free rotation of the cables preventing their entanglement. These low voltage signals are amplified by an electronic signal processing unit, located outside of the turbine and on the dry. The motor shaft is connected to the rotor shaft through a motor-gearbox (ratio 1:26) enabling suitable torque and rotation speed ratings.

Default calibrations provided by the manufacturer are used for the entirety of the programme. The accuracy of the instrumentation according to the service provider can be found in Table 3. These values are used to undertake an uncertainty analysis for all the test programmes.

The accuracy of the encoder is $1 R P M$. However, due to the gearbox ratio (1:26), the accuracy of the rotor rotation is calculated as $1 / 26=0.04 R P M$.

Table 3. Measuring range and accuracy of turbine instrumentation.

\begin{tabular}{ccc}
\hline Measured Signal & Operating Range & Accuracy \\
\hline Thrust & $500 \mathrm{~N}$ & $0.2 \%$ \\
Torque & $50 \mathrm{~N} \cdot \mathrm{m}$ & $0.2 \%$ \\
\hline
\end{tabular}

\subsubsection{Flow Measurement and Locations}

The flow stream is characterised in the absence of the turbine (bare-basin) and while the turbine is in operation (synchronised). An Acoustic Doppler Velocimeter (ADV) is selected to perform this measurements based on its light-weight and small dimensions. The ADV is placed in line with the rotor plane at a distance of $1.2 \mathrm{~m}(1.6 \mathrm{D})$ along the longitudinal section of the tank (see Figure 3). At IfREMER and FLOWAVE, the ADV is mounted independently of the turbine. Seeding particles are deposited in the tank and continuous flow circulation permits a good dispersion throughout the flow stream.

For the experiments at CNR-INM, the ADV is mounted to the towing carriage. In addition, a seeding mast mounted on the carriage is placed 5.5D upfront of the ADV. The seeding mast consists of a cylinder beam of $15 \mathrm{~mm}$ in diameter supporting a tube of $8 \mathrm{~mm}$. 
Twenty openings along a vertical section of $800 \mathrm{~mm}$ releases the seeding particles. The default accuracy of the ADV is reported as $\pm 1 \%$ of the measured value [23], i.e., $\pm 0.01 \mathrm{~m} / \mathrm{s}$ for a flow velocity of $1.0 \mathrm{~m} / \mathrm{s}$. However, an adequate operation of this device also depends on the density of particles in the water. In order to account for this, the signal correlation is preserved for the entirety of the experiments at a rate higher than $80 \%$, hence the reason for using a seeding mast at the tow tank (CNR-INM). Furthermore, ADV measurements are corrected for the presence of spikes by using the method proposed by [24].

The use of flow measurement equipment in tow tanks and for tidal stream applications is scarce in the literature, especially when referring to ADV technology. Therefore, this research attempts to evaluate its applicability when capturing flow characteristics in both current-only and wave-current combinations as well as the measurement location.

The flow stream is characterised in each of the facilities with the ADV and the wave gauges, and with and without the turbine for all the testing conditions. For the bare-basin measurements, the position of the ADV is exactly the same as the rotor hub when operated, i.e., at $x=0$ (Figure 3). As presented by [15], depending on the facility, three or five ADV measurement points evenly spread along the vertical and horizontal axis are acquired over the turbine swept area in order to quantify any vertical or lateral velocity gradient (Figure 4).

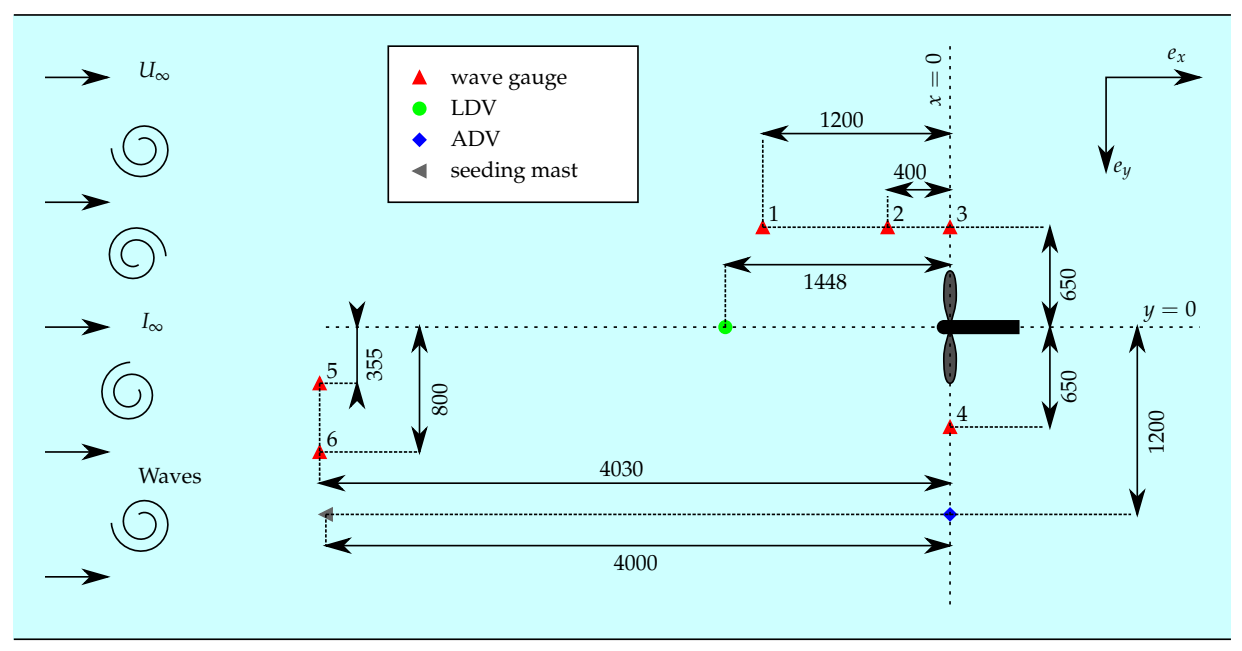

Figure 3. Schematic top-view of the test set-up used in the three tanks. The ADV is used at IFREMER, FlOWAVE and CNR-INM. The LDV is only used at IFREMER. The seeding mast is required at CNR-INM only. The wave gauges 1 to 3 are used at IFREMER and FLOWAVE and 3 to 6 at CNR-INM. Dimensions are given in $\mathrm{mm}$ and the presented tank width represents the IFREMER size.

One identified challenge in the field of tidal energy is to adequately characterise the onset flow to calculate the turbine's non-dimensional parameters (see Section 2.5.2). An attempt to overcome this issue is undertaken by [25], where the authors recommended to carry out flow velocity measurements at least $2 D$ upstream of the turbine when the turbulence rate is high. This procedure thus helped to better account for the velocity fluctuations perceived in synchronisation with the turbine. Another approach presented by [26] recommends to use the statistical mode of the velocity recorded instead of the mean velocity when calculating the performance coefficients. Using the mode of the flow velocity, differences in the performance coefficients of up to $12 \%$ are obtained when compared to the values obtained with the mean of the flow velocity. 


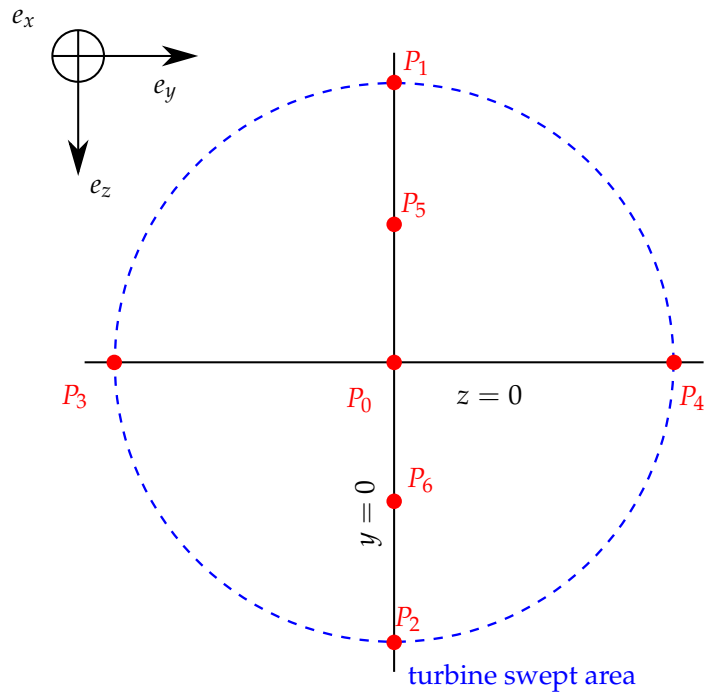

\begin{tabular}{lccc}
\hline point & $x$ & $y$ & $z$ \\
\hline$P_{0}$ & 0 & 0 & 0 \\
$P_{1}$ & 0 & 0 & $-D / 2$ \\
$P_{2}$ & 0 & 0 & $D / 2$ \\
$P_{3}$ & 0 & $-D / 2$ & 0 \\
$P_{4}$ & 0 & $D / 2$ & 0 \\
$P_{5}$ & 0 & 0 & $-D / 4$ \\
$P_{6}$ & 0 & 0 & $D / 4$ \\
\hline
\end{tabular}

Figure 4. Front view of the ADV measurement points describing the swept area of the turbine and their coordinates expressed in diameter $D=0.724 \mathrm{~m}$. Points 0 to 2 and 5 and 6 are acquired at IfREMER. Points 0 to 2 are acquired at CNR-INM. Points 0 to 4 are acquired at FLOWAVE.

In addition to the utilisation of an ADV, at IFREMER, the flow is also monitored using a Laser Doppler Velocimeter (LDV). While the ADV is able to measure three flow velocity components, the LDV available at IFREMER can capture two components: $u$ which is related to the flow direction $e_{x}$ and $v$ the horizontal component related to $e_{y}$ as seen in Figure 3. The LDV is installed $2 D$ upstream from the turbine, this distance is chosen based on previous experiences from the authors in order to obtain a closer representation of the flow "perceived" by the rotor while preserving a non-intrusive measurement [25]. The focal point of the laser beam (i.e., the measurement point, $0.53 \mathrm{~m}$ from the probe) is set to be in-line with the turbine hub, at $1.0 \mathrm{~m}$ water depth. The accuracy of the LDV is $\pm 0.1 \%$ [27]. This experiment is limited to the IFREMER facility due to difficulties arising with the transportation of the LDV to other laboratories.

A number of wave probes are also placed next to the turbine to verify the wave parameters set for each of the case scenarios. Three resistive wave probes are used at the facilities in IFREMER and FLOWAVE [15]: probes 1-3 as seen in Figure 3. A mix of resistive, ultrasound and dynamic wave probes is used in the CNR-INM tow tank: probes 3-6 as seen in Figure 3, where probes 4 and 6 are ultrasound wave gauges and probe 5 is a dynamic wave gauge. One single identical resistive wave probe is used in all facilities (probe 3 ). This is a crucial aspect of the test campaign, especially since the flow characteristics impacted by the addition of waves are deemed to be relevant between facilities.

\subsection{Experimental Plan}

The flow velocity or carriage velocity is set to 0.8 and $1.0 \mathrm{~m} / \mathrm{s}$. This flow velocity corresponds to a Reynolds numbers between $5.8 \times 10^{7}$ and $7.2 \times 10^{7}$, based on the turbine diameter and are representative of full scale velocities of 3.5 and $4.5 \mathrm{~m} / \mathrm{s}$, respectively. These flow speeds are chosen based on the capabilities of the laboratories which in some cases cannot operate at faster flows when waves are generated in combination with currents. According to [28-31], flow velocities around UK waters reach maximum values between 3.5 and $4.0 \mathrm{~m} / \mathrm{s}$ and turbulence intensities ranging from 10 to $20 \%$.

Four regular waves in-line with the current are chosen with wave frequencies between 0.5 and $0.7 \mathrm{~Hz}$ and wave amplitudes between 35 and $75 \mathrm{~mm}$. The wave amplitude and frequency are selected based on information provided by the facilities where some can achieve better wave properties at certain frequencies than others, especially when combined with current. One irregular wave setting is included in the test plan with a maximum wave frequency of $f_{\max }=0.6 \mathrm{~Hz}$ and a significant wave height of $H_{s}=0.1 \mathrm{~m}$. At full scale, these 
wave parameters are associated with wave amplitudes between 0.7 and $1.5 \mathrm{~m}$ and wave frequencies between 0.12 and $0.18 \mathrm{~Hz}$ (periods between 5.5 and $7.8 \mathrm{~s}$ ). According to [32], ordinary gravity waves with periods around $7 \mathrm{~s}$ have the largest relative height and are the ones a tidal turbine will be subjected to more frequently. Although the waves tested might be considered small compared to real sea states, the aim of the RRT is to repeat the same conditions in different facilities and to assess the impact on the turbine. Therefore, the selected wave conditions are theoretically replicable at all the facilities and, as it will be seen in Section 3.3, a periodic velocity component is generated. The summary of the tested flow conditions is presented in Table 4.

Table 4. Summary of the test matrix.

\begin{tabular}{cccccc}
\hline Case & Type & $\begin{array}{c}\text { Flow Speed } \\
{[\mathbf{m} / \mathbf{s}]}\end{array}$ & $\begin{array}{c}\text { Wave } \\
\text { Frequency }\end{array}$ & $\begin{array}{c}\text { Wave } \\
\text { Amplitude [Hz] }\end{array}$ & $\begin{array}{c}\text { Facilities Tested } \\
\text { at [mm] }\end{array}$ \\
\hline 1 & current & 0.8 & & & IFR, CNR, FLW \\
2 & regular & 0.8 & 0.6 & 75 & IFR, CNR, FLW \\
3 & regular & 0.8 & 0.5 & 35 & IFR, CNR, FLW \\
4 & current & 1.0 & & & IFR, CNR, FLW \\
5 & regular & 1.0 & 0.7 & 75 & IFR, CNR \\
6 & regular & 1.0 & 0.6 & 55 & IFR, CNR, FLW \\
7 & irregular & 0.8 & $0.6^{\#}$ & $100^{*}$ & IFR, CNR, FLW \\
\hline
\end{tabular}

$\# f_{\text {peak }}$ Peak frequency See [15]; ${ }^{*} H_{s}$ Significant wave height See [15].

For each of the test cases, eleven rotational speed settings are considered. These range from 0 to $148 R P M$ for flow velocities of $0.8 \mathrm{~m} / \mathrm{s}$ and from 0 to $185 R P M$ for flow velocities of $1.0 \mathrm{~m} / \mathrm{s}$. Maximum values are close to free-wheeling operation. To quantify the uncertainty of the experiment, repeated tests are considered for each case for several rotational speeds. Due to time limitations and the long wait between tests at CNR-INM, the test matrix is constricted to five rotational speeds per case plus two rotational speeds for the repeated tests. Note that the repeated tests are performed at the end of the test programme to allow for a randomised data acquisition while ensuring a time-efficient test campaign.

\subsection{Data Acquisition and Testing Procedure}

All signals are acquired using National Instruments (USA) hardware and in-house electronics developed by IFREMER staff. The signals are mostly sampled at a frequency $\left(f_{s}\right)$ of $128 \mathrm{~Hz}$, which allows the capture of the dynamic loads inherent from the turbine. This sampling frequency should suffice to describe the performance of the device adequately; however, larger sampling rates should be used for other vibration analysis.

Flow and water surface elevation measurements were synchronised with the turbine instrumentation by means of a short impulse trigger signal. The surface elevation is captured at the same sampling rate as the turbine signals. The ADV was, however, set to acquire data at a different rate depending on the facility, $128 \mathrm{~Hz}$ in the tow tank (CNR-INM) and $64 \mathrm{~Hz}$ in IFREMER and FLOWAVE.

\section{Testing Procedure}

To ensure that all the tests are performed similarly, the following test procedure is agreed between partners.

For recirculating flumes and tanks (i.e., IFREMER and FLOWAVE):

1. zero values are first recorded at stagnant conditions for $30 \mathrm{~s}$; i.e., water still and parked turbine,

2. the flow is set to the required speed,

3. the waves are imposed; i.e., initiate operation of the wave-makers (if applicable),

4. set the rotational speed of the turbine (starting at zero $R P M$ )

5. start recording,

6. stop recording,

7. repeat steps 4,5 , and 6 for other $R P M$ settings, 
8. stop the wavemaker,

9. stop the flow,

10. park the turbine.

For towing tanks (e.g., CNR-INM), the process is similar to the process described above. However, the wavemakers and turbine rotation are initiated before the carriage moves.

In the flumes, $128 \mathrm{~s}$ of measurements are acquired for the current-only conditions, $256 \mathrm{~s}$ for the regular wave experiments and $512 \mathrm{~s}$ for the irregular wave condition. These test durations are adopted in order to reach a convergence rate depending on the fluctuation of the signals that are reported in Section 3.6.

The time duration adopted in the tow tank differs due to the inherent finite length of the tank but also due to the homogeneous nature of the flow (i.e., no turbulence). For the tow-only and wave-tow conditions, $50 \mathrm{~s}$ and $140 \mathrm{~s}$ are recorded, respectively. Although shorter than the tests at the recirculating flume and tank, at a carriage speed of $1.0 \mathrm{~m} / \mathrm{s}$, about 20 wave periods are achievable with good convergence. For the irregular wave case, however, tow tank repetitions are gathered until $420 \mathrm{~s}$ of data are acquired. This time is equivalent to approximately 250 wave encounters at $f=0.6 \mathrm{~Hz}$.

\subsection{Data Analysis}

\subsubsection{Flow Characterisation}

The flow velocity records from the flow characterisation procedure are processed to define the incoming (far upstream) velocity $U_{\infty}$. As suggested by [33], the square or cubing of the velocity is performed prior to temporal and spatial averaging. The average velocity is then computed as a Disc-Integrated Velocity Average (DIVA) that serve as an input for the calculation of non-dimensional parameters of power and thrust. The DIVA method is described and employed in the associated work done in [15].

In this work, only analysis of the $u$ flow component is explored due to the amount of data gathered during these tests. However, the analysis of the $v$ and $w$ flow components is presented in [15].

\subsubsection{Turbine Performance}

The turbine performance is characterised using three essential parameters: the mean hydrodynamic torque, $Q$ in $N \cdot m$, the mean thrust, $T$ in $N$ and the angular velocity of the turbine, usually represented by $\omega$ in $\mathrm{rad} / \mathrm{s}$, or as rotational speed using revolutions per minute $R P M$. In this investigation, these operational characteristics are evaluated and presented focusing on the repeatability of the experiment and the uncertainty analysis between tests.

Another common approach is to represent the performance of a tidal device with non-dimensional parameters of power coefficient $C_{P}$ and thrust coefficient $C_{T}$, which are explored in [15].

\subsection{Uncertainty Analysis}

When possible, the full test cases have been repeated at each facility. This information is deemed necessary to undertake an uncertainty analysis based on a combined expanded uncertainty using precision and bias errors.

The precision uncertainty, $u_{A}$ is calculated based on the standard deviation obtained from the repeated tests $(s)$ and the number of repetitions $(n)$, as displayed in Equation (1). The bias uncertainty $\left(u_{B}\right)$ is quantified based on the accuracy of the instrument as provided in Table 3.

The combined expanded uncertainty is thus calculated based on Equation (2), using a coverage factor $k=2$ which gives a level of confidence of nearly $95 \%$ as reported by [34]. The combined uncertainty is presented as a percentage of mean value for better interpretation. This analysis is based on the recommendations made by [16,35]. Further 
calculations are required when looking at error propagation of other parameters; for example, when power and thrust coefficients are calculated, as it is described in [35].

$$
\begin{gathered}
u_{A}=\frac{s}{\sqrt{n}} \\
u_{T}=\sqrt{u_{A}^{2}+u_{B}^{2}} k
\end{gathered}
$$

\subsection{Signal Stabilisation}

To have a better understanding of how much a signal (i.e., thrust or flow velocity) deviates from the average of a full time series, the Root-Mean-Square Error (RMSE) is used [36]. The RMSE is calculated in $1 \mathrm{~s}$ windows. The units of the RMSE are the same as the units of the signal being analysed:

$$
R M S E=\sqrt{\frac{\sum_{t=1}^{T}\left(\hat{y}_{[1, t]}-y_{T}\right)^{2}}{t}}
$$

where $t$ is time in seconds, $T$ is the total duration of the time series, $\hat{y}_{[1, t]}$ is the average of the signal from the beginning of the test to the value of $t$, and $y_{T}$ is the average of the signal for the whole time series.

\section{Results and Discussion}

\subsection{Flow Velocity Characterisation (Bare-Basin)}

In this section, the flow characteristics obtained at each of the facilities are studied using the data recorded in the absence of the turbine, here defined as "bare-basin". Figure 5 shows an extract of the time history and the Power Spectral Density (PSD) of the streamwise component of the velocity $u$ for current-only case 1 , measured at $z=-R$, i.e., at point P1 (Figure 4) corresponding to the top-dead centre of the rotor. For the FLOWAVE record, large velocity variations are noticeable in the time history: with values varying between 0.6 and $1.0 \mathrm{~m} / \mathrm{s}$. The corresponding energy level observed in the PSD is the highest one comparing to the spectra obtained in the other facilities. This spectra follows the classical $-5 / 3$ power law, corresponding to the Kolmogorov energy cascade. For IFREMER, the flow straightener limits the turbulence and makes the flow anisotropic. That is the reason why the $-5 / 3$ power law is only noticeable between $f=1.10^{-1}$ and $1.10^{0} \mathrm{~Hz}$. For CNR-INM, the PSD is fairly constant versus the frequency because there is no flow, hence no turbulence. An energy spike is visible at $f \simeq 5.5 \mathrm{~Hz}$, corresponding to ADV probe vibrations.
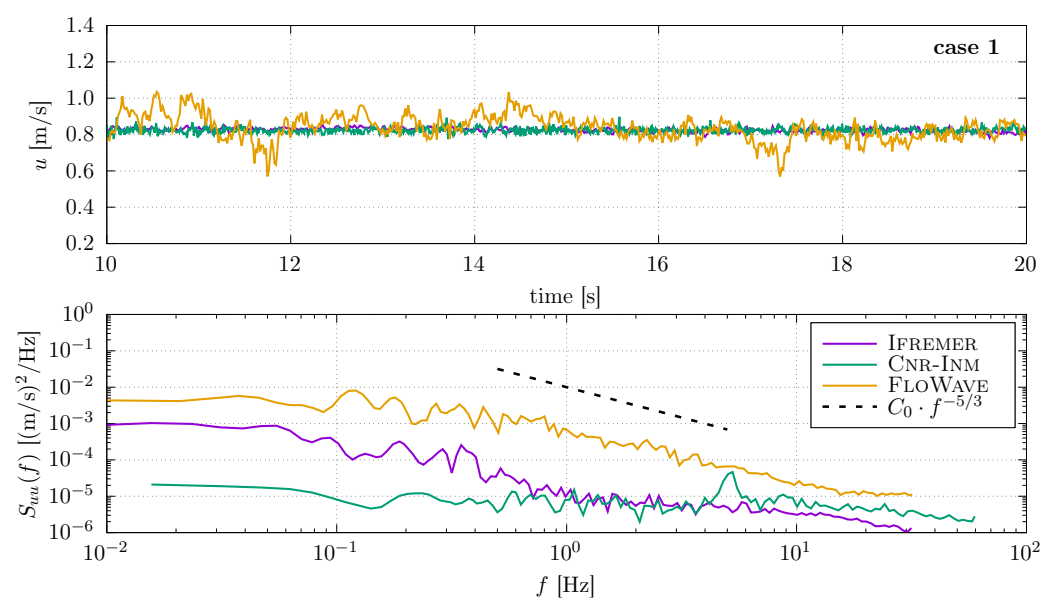

Figure 5. Time histories (top) of the ADV streamwise velocity $u$ measured at the top-dead centre of the rotor for case 1 and their corresponding PSD (bottom) at IFREMER, FLOWAVE and CNR-INM. The PSD panel also includes Kolmogorov's - 5/3 power law. 
In Figure 6, time history at IFREMER shows slightly higher velocity ranges than the other two facilities. In the frequency domain, flow velocity shows higher energy levels. These are associated with the flow disruptions and turbulence created by the position of the wavemaker located upstream of the test area. The $-5 / 3$ power law is clearly present at IFREMER and FLOWAVE. However, the spectra measured at FLOWAVE contains lower energy. The lowest one is spectra measured at the CNR-INM facility. Similar to case 1, the energy spectra at CNR-INM still presents the ADV probe vibrations at $f \simeq 5.5 \mathrm{~Hz}$. These vibrations are actually thought to be associated with a combination of carriage speed, wave conditions, and the ADV being mounted below the carriage (see Section 2.2.2). In all facilities, a periodic component with the same energy level is clearly visible on the PSD, indicating the wave orbital velocities for case 2 , with a wave frequency of $0.6 \mathrm{~Hz}$.
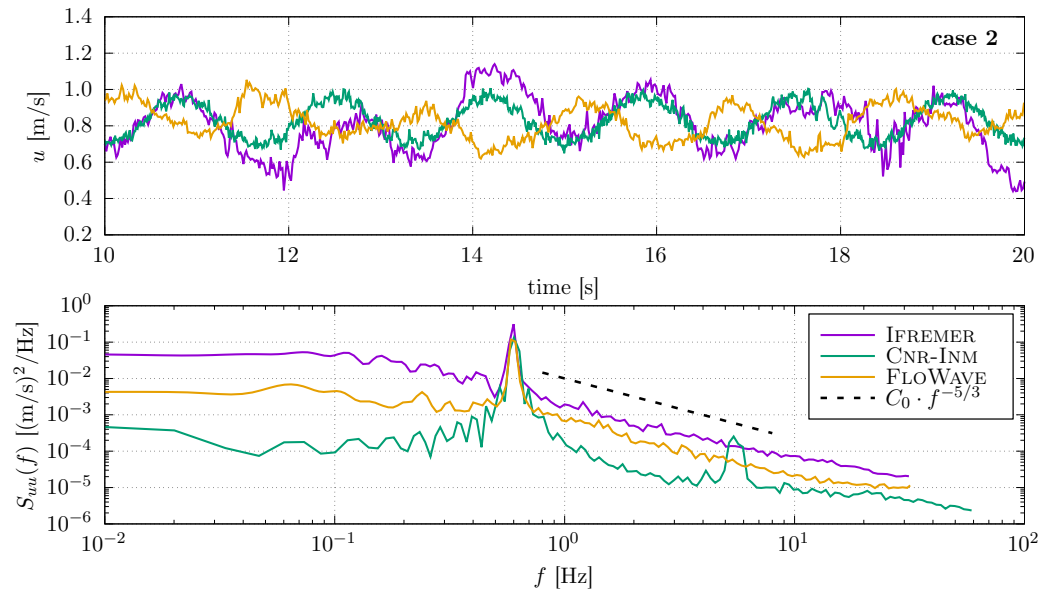

Figure 6. Time histories (top) of the ADV streamwise velocity $u$ measured the top-dead centre of the rotor for case 2 and their corresponding PSD (bottom) at IFREMER, FLOWAVE and CNR-INM. The PSD panel also includes Kolmogorov's - 5/3 power law.

The velocities obtained using the DIVA method for the flow characterisation (barebasin) are grouped together in Table 5 as presented in [15]. Although flow characterisation for case 6 at CNR-INM was not performed, turbine performance was measured for this case. All the average velocities recorded are higher than the nominal values of 0.8 and $1.0 \mathrm{~m} / \mathrm{s}$. The highest value for the $0.8 \mathrm{~m} / \mathrm{s}$ cases is for combined wave and current case 2 at IFREMER with average velocities $\approx 5.8 \%$ higher than the nominal velocity. For the $1.0 \mathrm{~m} / \mathrm{s}$ cases, case 5 with regular waves at IFREMER has the highest value at $5.6 \%$ above the nominal flow velocity. At IFREMER, average velocities for the combined wave and current cases are up to $3 \%$ faster than the current-only cases. This could be attributed to the velocity depth profile and the contribution of the waves to the flow velocity. At each facility, average flow velocities between cases are within $\sim 0.5 \%$.

At CNR-INM, however, it has been proven that the carriage speed has an accuracy of $\pm 1 \mathrm{~mm} / \mathrm{s}$. The differences between the DIVA method (Table 5) and the carriage speed could be attributed to the accuracy of the velocity measurement technique used.

Table 5. Disc-integrated velocity average (DIVA) values for the flow characterisation without turbine for all cases at all facilities. See Section 2.5.1, from [15].

\begin{tabular}{cccc}
\hline Case & IFREMER & CNR-INM & FLOWAVE \\
\hline 1 & 0.826 & 0.843 & 0.825 \\
2 & 0.848 & 0.848 & 0.827 \\
3 & 0.846 & N/A & 0.822 \\
4 & 1.024 & 1.037 & 1.036 \\
5 & 1.056 & 1.036 & N/A \\
6 & 1.047 & N/A & 1.031 \\
7 & 0.840 & N/A & 0.826 \\
\hline
\end{tabular}




\subsection{Flow Characterisation (with Operating Turbine)}

ADV measurements are also obtained throughout the test campaign with the ADV placed at $1.2 \mathrm{~m}$ from the turbine axis (see schematic on Figure 3) when operating and in synchronisation. Figures 7 and 8 show the variation of the average and standard deviation velocity for cases 1 and 2, respectively, with the turbine rotational speed. Table 6 shows the time and case average of the streamwise velocity $u$ for all cases at all facilities. Overall, average flow velocity at all facilities is higher than the nominal velocities, i.e., similar behaviour seen in the bare-basin measurements in Table 5. For the current-only case (case 1), FLOWAVE presents flow velocities 10\% higher than the nominal velocity. With the addition of regular waves (case 2), FLOWAVE and IFREMER have flow velocities $10 \%$ higher than the target velocity. In contrast, flow velocity at CNR-INM is closer to the target value. Results obtained with the DIVA method (Table 5) present higher values than the ADV at FLOWAVE and IFREMER and lower values at CNR-INM. These differences are mainly attributed to blockage effects and rotor-induced velocities.

Notably, there is certain fluctuation in the flow velocity depending on the turbine's rotational speed. The influence from the operating turbine may explain the discrepancies of the results. It is worth noting that the LDV (Section 3) is located upstream of the turbine, where the rotor-induced velocity has a negative contribution to the upstream current, whereas the ADV is located next to the rotor, where the contribution of the rotor-induced velocity is positive due to the by-pass effect.
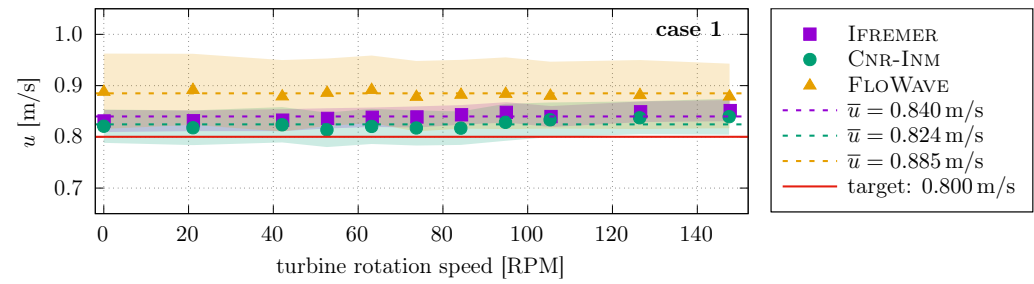

Figure 7. Time average (markers) and standard deviation (shading) of the ADV stream-wise velocity $u$ versus turbine rotational speed for current-only case 1 at all facilities. Dashed lines are the average of $u$ for case 1 at all rotational speed settings per facility; the red line is the target value of $0.8 \mathrm{~m} / \mathrm{s}$.

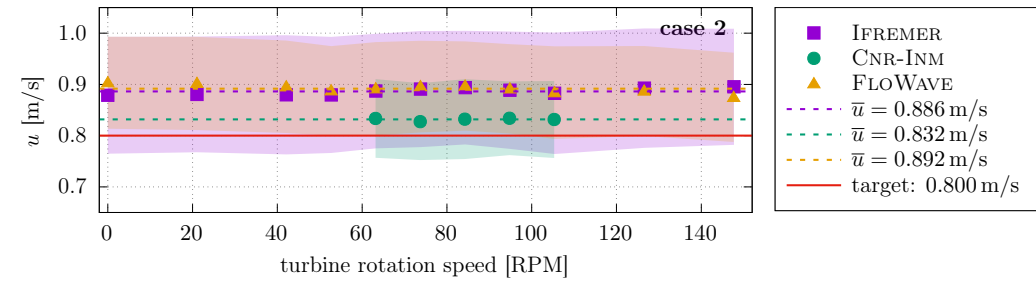

Figure 8. Time average (markers) and standard deviation (shading) of the ADV stream-wise velocity $u$ measured in synchronisation with the turbine against turbine rotational speed for wave and current case 2 at all facilities. Dashed lines are the average of $u$ for case 2 at all rotational speed settings per facility. Red line is the target value of $0.8 \mathrm{~m} / \mathrm{s}$.

Table 6. Time and case average of the ADV stream-wise velocity $u$ for all cases at all facilities. ADV mounted at $x_{A D V}=0$ and $y_{A D V}=1200 \mathrm{~mm}$ as seen in Figure 3 .

\begin{tabular}{cccc}
\hline \multirow{2}{*}{ Case Number } & IFREMER & CNR-INM & FLOWAVE \\
\cline { 2 - 3 } & & $\overline{\boldsymbol{u}}[\mathbf{m} / \mathbf{s}]$ & 0.885 \\
1 & 0.840 & 0.824 & 0.892 \\
2 & 0.886 & 0.832 & 0.886 \\
3 & 0.869 & 0.840 & 1.105 \\
4 & 1.050 & 1.025 & - \\
5 & 1.094 & 1.042 & 1.103 \\
6 & 1.084 & 1.039 & 0.890 \\
\hline
\end{tabular}


To further investigate this discrepancy, a comparison between the ADV and the LDV data for current-only case 1 at all facilities is presented in Figure 9. At all rotational speed values, the velocity measured by the ADV is higher than the one measured by the LDV ( $2 D$ upstream of the turbine) and than the nominal flow velocity in all facilities. As seen in Figure 3, the distance between probes is quite large: $x_{L D V}=-1448 \mathrm{~mm}$ and $y_{L D V}=0$, whereas $x_{A D V}=0$ and $y_{A D V}=1200 \mathrm{~mm}$. As the rotational speed increases, the LDV measurements decrease and the ADV measurements increase at IFREMER and CNR-INM. At FLOWAVE, however, behaviour is the opposite. As the rotational speed increases, the flow velocity decreases. At $R P M=0$, the LDV has the same measurements as the nominal flow velocity. However, the ADV measurements are about 3\% higher at CNR-INM, 5\% higher at IFREMER and 11\% higher at FLOWAVE. At the highest RPM values, the LDV measurement is $2 \%$ lower than the nominal velocity, whereas the ADV measurement is $>6 \%$ higher at all facilities. Due to these differences, it is concluded that the synchronous measurement obtained with the ADV on the side of the turbine, especially with high blockage ratios, is influenced by the presence of the turbine and its rotation effect in all facilities. It is related to the bypass of the flow around the turbine increasing with the turbine rotation.
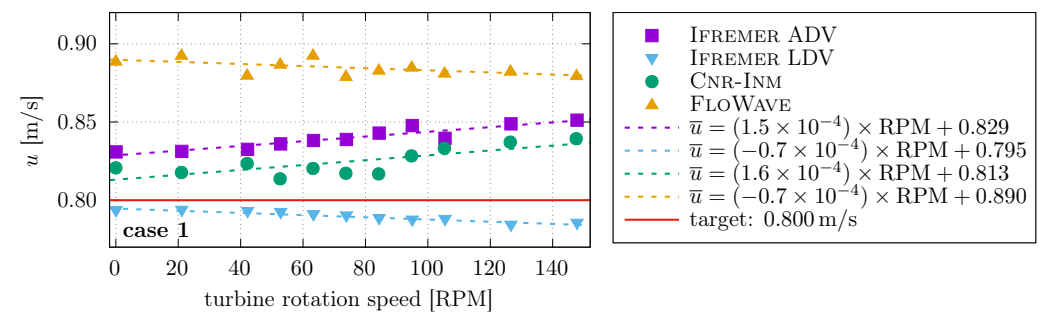

Figure 9. Variation of the time-averaged (markers) and linear regression (dotted lines) of the ADV and LDV (only at IFREMER) stream-wise velocity $u$ in synchronisation with the turbine against the turbine rotational speed for case 1 at all facilities. The red line indicates the target velocity of $0.8 \mathrm{~m} / \mathrm{s}$.

\subsection{Wave Orbital Velocities and Surface Elevation}

Due to the fluctuating characteristics of the waves obtained (Figure 8), similarly to [15], the instantaneous values of the velocity time series of the LDV (Figure 3) are analysed using the Hilbert transform. A Fast Fourier Transform (FFT) is also performed to quantify the amplitude of the waves.

Figure 10 shows the amplitude of the Hilbert transform of the stream-wise velocity $u$ measured by the ADV in synchronisation with the turbine parameters for case 2, presented against the rotational speed. The time-average of the horizontal wave orbital $u$ for all the wave cases is shown in Table 7. The average and standard deviation of the Hilbert transform is higher at IFREMER than at CNR-INM by 37\%. At FLOWAVE, measurements are only $8 \%$ higher. The higher average velocities at IFREMER are due to the higher wave amplitudes (Figure 11). However, the high standard deviation values at IFREMER and FLOWAVE are due to interaction between wave and current.
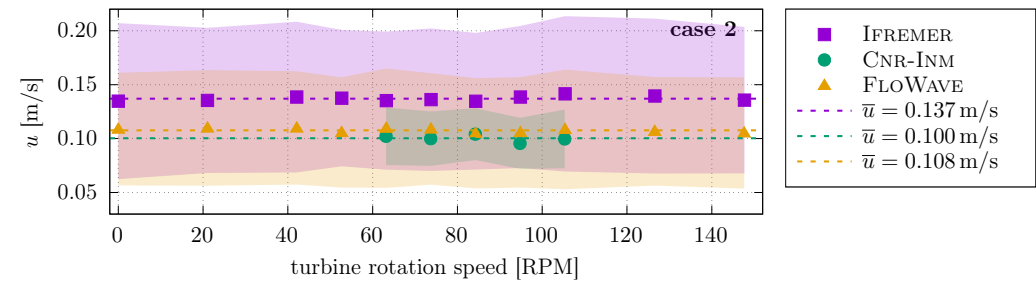

Figure 10. Variation of the time-averaged (markers) and standard deviation (shading) of the horizontal wave orbital velocity $u$ with rotational speed for case 2 at all facilities, obtained with the ADV. Dashed lines are the average of horizontal wave orbital for case 2 at all rotational speed settings per facility. 
Table 7. Time-average of the horizontal wave orbitals $u$ measured by the ADV at the turbine hub height for all cases at all facilities.

\begin{tabular}{cccc}
\hline \multirow{2}{*}{ Case Number } & IFREMER & CNR-INM & FLOWAVE \\
\cline { 2 - 4 } & & $\bar{u}[\mathbf{m} / \mathbf{s}]$ & \\
\hline 2 & 0.137 & 0.100 & 0.108 \\
3 & 0.119 & 0.056 & 0.086 \\
5 & 0.136 & 0.094 & - \\
6 & 0.139 & 0.082 & 0.102 \\
7 & 0.088 & 0.038 & 0.087 \\
\hline
\end{tabular}

The free surface elevation measured with wave probe 3 (Figure 3) in synchronisation with the turbine parameters for case 2 using the Hilbert transform is presented in Figure 11. As seen previously in the flow velocity data in Figure 6, the wave probe data shows that, for all wave cases, the average wave amplitude is higher at IFREMER. Comparing the results with the nominal values (see Table 8 ), average wave amplitudes differences at IFREMER range from -20 to $16 \%$, from -30 to $-9 \%$ at CNR-INM and from -53 to $-20 \%$ at FLOWAVE, versus the case number. The inability to accurately account for such broad ranges is thought to be due to the difficulty it entails to generate waves in recirculating tanks [37]. The use-or lack thereof-of wave amplitude corrections in the presence of currents or the wave generation techniques deployed in an incoming flow can explain such variations. At IFREMER, waves are generated with the addition of a wavemaker located upstream of the measurement area, at CNR-INM waves are generated in steady water and at FLOWAVE a circular array of paddles behind the current turning vanes generates the waves. In addition, uncertainties related to the resistive wave gauges may play a minor role (in the order of millimetres) in the different wave amplitudes seen between facilities.

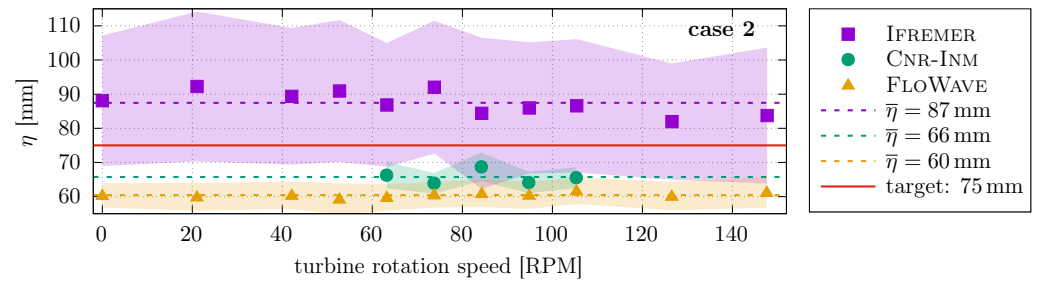

Figure 11. Variation of the average (markers) and standard deviation (shading) of the wave amplitude $\eta$ with rotational speed for case 2 at all facilities. Dashed lines are the average of the wave amplitude for case 2 at all rotational speed settings per facility. The red line indicates the target wave amplitude of case 2, data obtained with wave probe 3 (see Figure 3).

Table 8. Time and case average of the wave amplitude $\eta$ for all cases at all facilities. Data obtained from wave probe 3 (see Figure 3) in synchronisation with the turbine.

\begin{tabular}{ccccc}
\hline \multirow{2}{*}{ Case Number } & Target & IFREMER & CNR-INM & FLOWAVE \\
\cline { 2 - 5 } & \multicolumn{3}{c}{$\eta[\mathbf{m m}]$} \\
\hline 2 & 75 & 87 & 66 & 60 \\
3 & 35 & 37 & 30 & 26 \\
5 & 75 & 72 & 62 & - \\
6 & 55 & 61 & 50 & 26 \\
7 & $100 *$ & 40 & 35 & 35 \\
\hline
\end{tabular}

* Significant wave height $H_{S}$.

Another method to calculate the wave heights is to use zero-up crossing techniques. In Figure 12, a visual representation of the zero-up crossing method for calculating the wave height $H$ (i.e., $\eta \times 2$ ) is presented. Firstly, a Loess filter using a span of $0.09 \%$ of the total number of samples is used to remove high frequency noise. Once the data are smooth, 
each wave period is calculated when the code detects a zero-up crossing (pink circles). Then, the wave height is calculated by measuring the distance between the maximum and minimum values within each period (grey rectangles). Figure 13 shows the average wave heights for all cases at all facilities. Wave probe number 3 in the $x$-axis is the wave probe used in all the facilities (Figure 3).

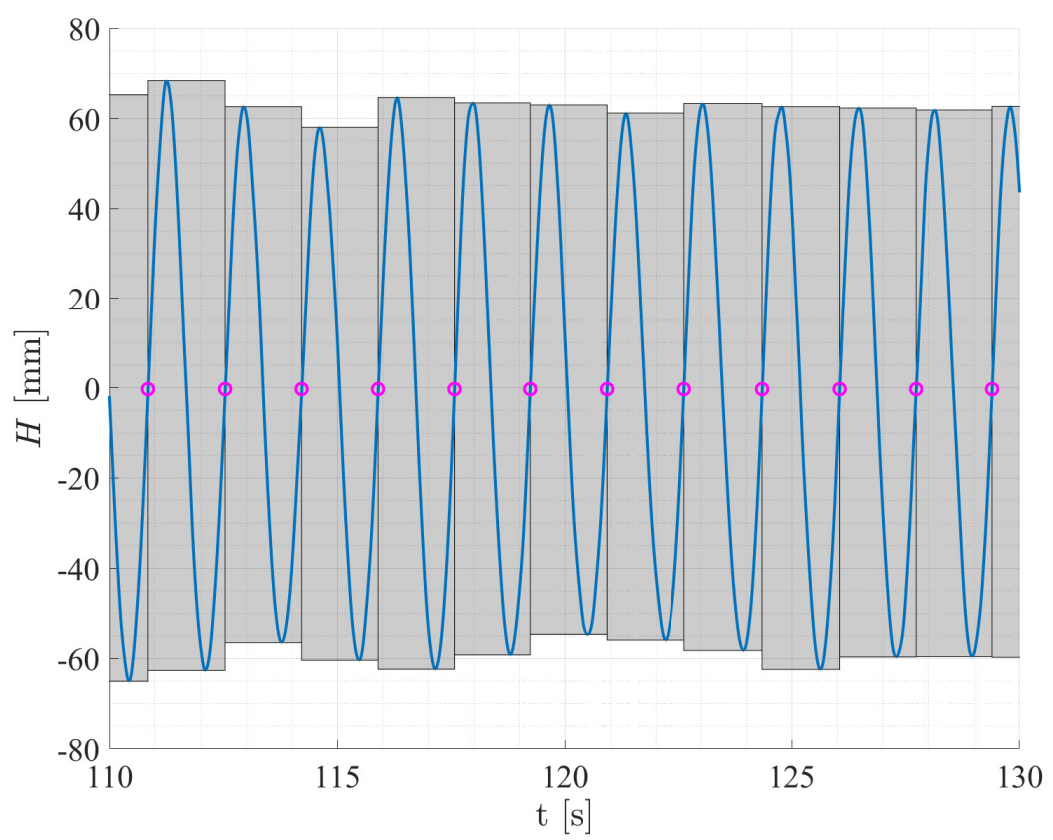

Figure 12. Visual representation of the zero-up crossing method. Pink circles represent every time the signal crosses zero from negative to positive. The width of the greyed areas indicates the wave period and the height indicates the wave height.

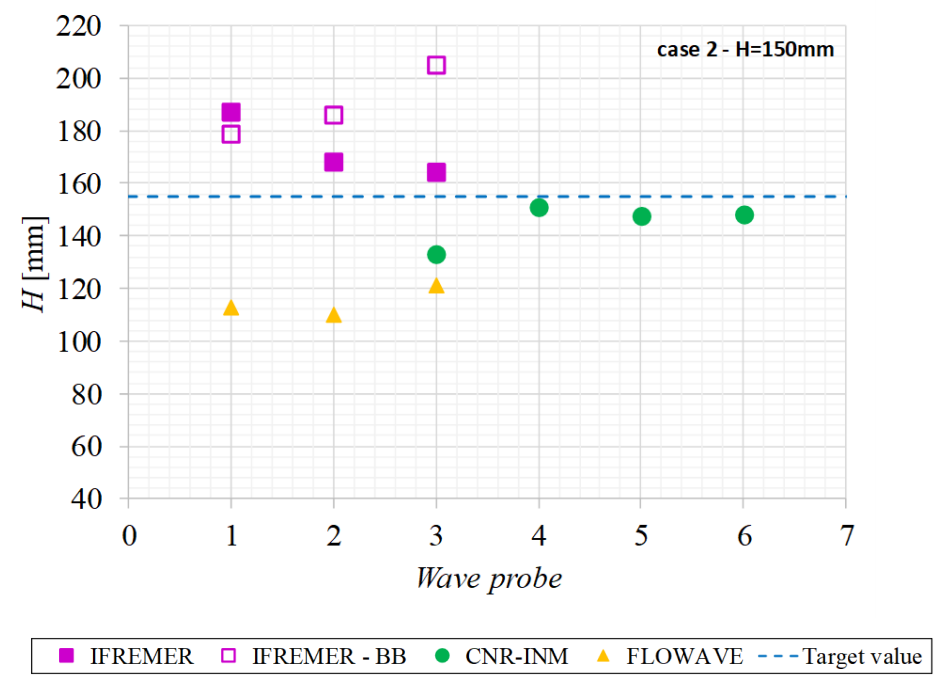

Figure 13. Wave height $H$ comparison between the different wave probes at each facility for case 2 . IFREMER-BB are the bare-basin, flow characterisation tests. Dashed line represents the target wave height for case 2 of $H=150 \mathrm{~mm}$. For the physical location of each wave probe, refer to Figure 3.

At CNR-INM, wave probes 3 and 4 are in the same plane, but the value of probe 4 is $15 \%$ higher than that of probe 3 . This difference could be associated with the different types of wave probes. Wave probe 3 is the capacitive wave probe used at all facilities, whereas wave probe 4 is ultrasonic. Wave probes 5 (dynamic) and 6 (ultrasonic) are also in the same plane, but their measurements are the same. The difference between the capacitive wave 
probe and the others could be an indication of lower accuracy or calibration errors of the probe. Despite these differences, the waves generated at CNR-INM are the ones closer to the nominal values.

At IFREMER, the average wave height seems to decrease as it gets closer to the rotor. However, for the bare-basin tests (IFREMER BB), the wave height increases closer to the rotor plane. This, for all cases except for case 5, showcasing the influence of the turbine in the upstream flow.

The data retrieved from FLOWAVE seems to have the most unpredictable values. Differences between wave probes are within $10 \%$. However, the average values can be up to $50 \%$ (case 6) short of the preset values but as close as 15\% (case 3) of the predefined values. Further work needs to be undertaken to characterise in detail the flow conditions, which is limited during this test campaign. It has been shown [37] that generating high amplitude waves at high frequencies when flow velocity is higher than $0.5 \mathrm{~m} / \mathrm{s}$ is difficult at FloWAVE.

Wave heights of all cases calculated with the zero-up crossing (Figure 13) show similar values within $10 \%$ compared to the values using the Hilbert transform approach from Figure 11.

\subsection{Turbine Performance}

The results presented in this section are all the physical values representing the operation of the turbine. Figures 14 and 15 show the tests for the $0.8 \mathrm{~m} / \mathrm{s}$ cases.

In general, the three facilities provide similar values of power and thrust for rotational speeds below $60 R P M$. It seems that, at the three facilities, the maximum power happens at around $85 R P M$.

Above the rotational speed at which maximum power is reached, CNR-INM provides values of power and thrust up to $20 \%$ lower than the other facilities. This behaviour is mostly related to the flow velocity data observed in Table 5, where the average flow velocity at CNR-INM is slower, yet closer to the nominal velocity, than at the other two facilities. The different blockage ratio between the tanks is shown to be another explanation for such a difference [15].

FLOWAVE provides similar power values for most of the rotational speed settings for the current-only case than at IFREMER. For the combined wave and current cases, however, values at IFREMER are predominantly higher. Compared to CNR-INM, values at FLOWAVE and IFREMER are up to $50 \%$ higher for case 1 and up to $30 \%$ for case 2 .

Thrust values at FLOWAVE and IFREMER are higher than at CNR-INM by up to $15 \%$ for all rotational speed setting available.

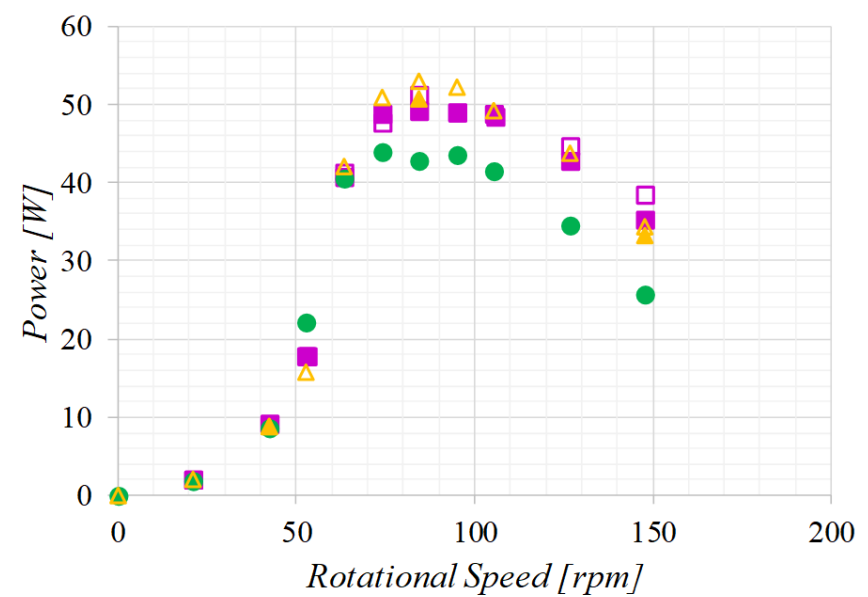

Figure 14. Cont. 


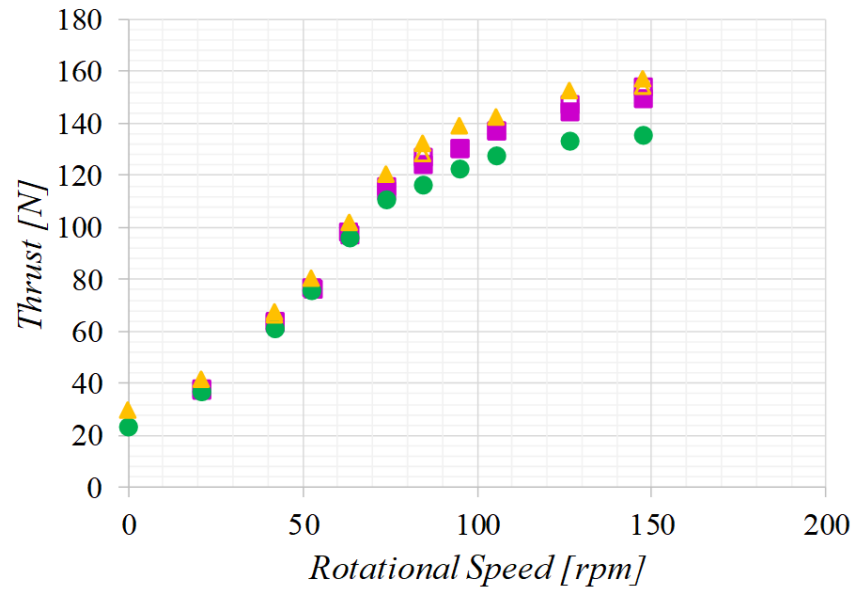

\begin{tabular}{|ll|}
\hline IFREMER & DIFREMER (REPEATS) \\
CNR-INM & O CNR-INM (REPEATS) \\
OFLOWAVE & $\triangle$ FLOWAVE (REPEATS) \\
\hline
\end{tabular}

Figure 14. Case 1: Variation of the time average of the power (top) and thrust (bottom) measurements against turbine rotational speed for cases at $0.8 \mathrm{~m} / \mathrm{s}$, taken at each of the facilities with the repeated tests when available.
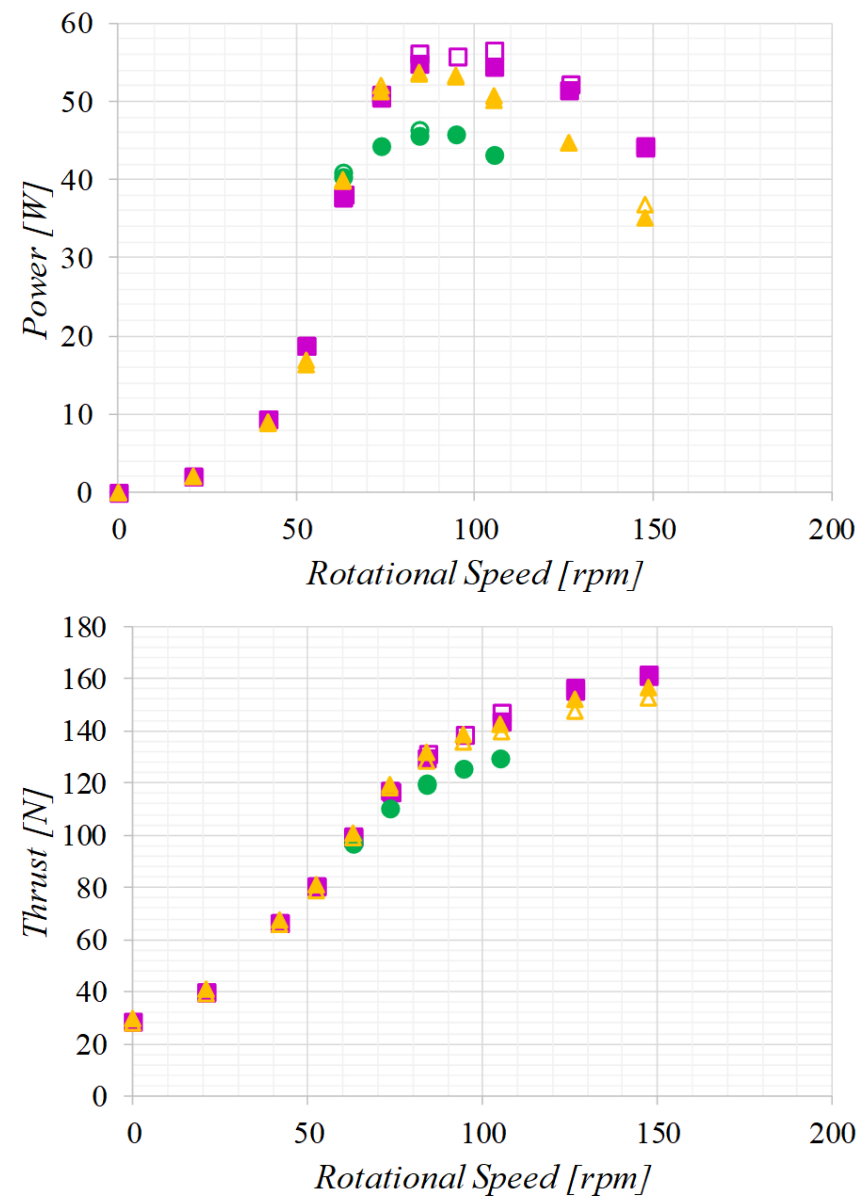

\begin{tabular}{|ll|}
\hline IFREMER & $\square$ IFREMER (REPEATS) \\
CNR-INM & O CNR-INM (REPEATS) \\
$\triangle$ FLOWAVE & $\triangle$ FLOWAVE (REPEATS) \\
\hline
\end{tabular}

Figure 15. Case 2: Variation of the time average of the power (top) and thrust (bottom) measurements against turbine rotational speed for cases at $0.8 \mathrm{~m} / \mathrm{s}$, taken at each of the facilities with the repeated tests when available. 
In most cases, the repeatability of the experiment seems to be of good quality, except for some cases where the repeat points are notably different, highlighting the requirement to repeat data-sets in turbulent flows. This discrepancies are studied further in Section 3.5.

\subsection{Uncertainty Analysis}

It is not a common practice to include uncertainty analyses from experimental trials within the tidal energy community yet. In fact, not many studies indicate if experiments have been replicated in order to measure any precision errors. In $[13,38]$, errors are reported in the region of 10\% (average torque and thrust) and 3\% (average power and thrust) for experiments undertaken in the IFREMER flume and the tow tank at the Kelvin-hydrodynamics lab (Strathclyde University), respectively. Both studies use the same equipment, but the investigations are unrelated; i.e., Murrat et al. [38] utilises this testing campaign to validate a numerical model and use tow-only conditions, whilst Ref. [13] explores the damping effects of bend-twist composite blades when operating under effects of waves and currents.

In the present research, average values of the uncertainty analysis done for the torque, thrust and rotational speed measurements for the three facilities with the help of Equations (1) and (2) are shown in Table 9. These values comprise the mean for all the test cases including regular and irregular wave-current conditions. Overall, these parameters show low uncertainty values in most of the experiments with average uncertainties as a percentage of mean values on the order of $2 \%$. It is evident, however, that the data gathered from FLOWAVE indicate a larger uncertainty in the experiments (between 3 and $4 \%$ ). The higher uncertainty values at FLOWAVE could be associated with the higher turbulence intensity (TI) values seen at FLOWAVE as observed in [15].

Table 9. Comparison of the combined expanded uncertainty as a percentage of the average value based on Equations (1) and (2).

\begin{tabular}{cccc}
\hline Facility & Torque [\%] & Thrust [\%] & Rotational Speed [\%] \\
\hline CNR-INM & 1.48 & 0.68 & 0.04 \\
FLOWAVE & 4.21 & 3.13 & 0.07 \\
IFREMER & 1.60 & 0.91 & 0.11 \\
\hline
\end{tabular}

The results from this section are also analysed in terms of case numbers and rotational speed (at $0.8 \mathrm{~m} / \mathrm{s}$ and $1.0 \mathrm{~m} / \mathrm{s}$ ). Tables 10 and 11 show the average uncertainty values from all the cases for torque and thrust, respectively. It is clear that the main contribution for a large uncertainty comes from the data gathered for case 4 and from the FLOWAVE facility, which is surprising, as this is a current-only condition and, therefore, the flow is less variable [15]. Looking into more detail, the largest uncertainty for case 4 (FLOWAVE) is related to peak power (105 RPM) and free-wheel conditions (184 RPM), where combined uncertainties as a percentage of mean values are higher than $14 \%$ and $7 \%$ for the torque and thrust values, respectively. However, only three cases are repeated for this experiment and also the uncertainty for the other case performed at $1 \mathrm{~m} / \mathrm{s}$ (case 6 ) shows low average uncertainty values for both torque and thrust measurements $(<2 \%)$. This highlights the importance of performing repeated tests, which, on occasion, could arise from some malfunctioning of the device or the flow generation. One relevant aspect that is not performed in this RRT and is advisable to other experimental tests is to repeat the flow characterisation at least at the beginning of the testing practice and, at the end, again to obtain any changes arising which may be due to the degradation of the current generation devices (or similar) over time. 
Table 10. Combined uncertainty for torque as percentage of mean value based on the case number for each facility [\%]. Current-only cases at CNR-INM have no repeats.

\begin{tabular}{cccc}
\hline \multirow{2}{*}{ Case } & \multicolumn{3}{c}{ Facility } \\
\cline { 2 - 4 } & CNR-INM & FLOWAVE & IFREMER \\
\hline 1 & - & 2.81 & 2.52 \\
2 & 1.45 & 1.44 & 1.31 \\
3 & 1.37 & 1.53 & 1.71 \\
4 & - & 15.28 & 1.93 \\
5 & 0.72 & - & 1.12 \\
6 & 0.78 & 1.90 & 1.30 \\
7 & - & 2.24 & 1.89 \\
\hline
\end{tabular}

Table 11. Combined uncertainty for thrust as percentage of mean value based on the case number for each facility [\%]. Current-only cases at CNR-INM have no repeats.

\begin{tabular}{cccc}
\hline \multirow{2}{*}{ Case } & \multicolumn{3}{c}{ Facility } \\
\cline { 2 - 4 } & CNR-INM & FLOWAVE & IFREMER \\
\hline 1 & - & 2.35 & 1.37 \\
2 & 0.76 & 2.84 & 0.98 \\
3 & 0.81 & 3.68 & 1.01 \\
4 & - & 7.74 & 0.88 \\
5 & 0.59 & - & 0.90 \\
6 & 0.54 & 1.15 & 1.00 \\
7 & - & 0.96 & 0.98 \\
\hline
\end{tabular}

When looking at the analysis in terms of turbine operating points; i.e., rotational speed in this work (Figure 16), the IFREMER torque data suggest that, as the turbine approaches the free-wheeling condition, the uncertainty slightly increases. The same can be said for the thrust values except for the first two points at high load conditions. A similar trend may be depicted from the two CNR-INM cases, but, due to the limited number of tests, this hypothesis can not be confirmed, especially since the FLOWAVE data do not show a clear pattern. This behaviour may be related to larger vibration from the turbine when this increases its rotational speed.

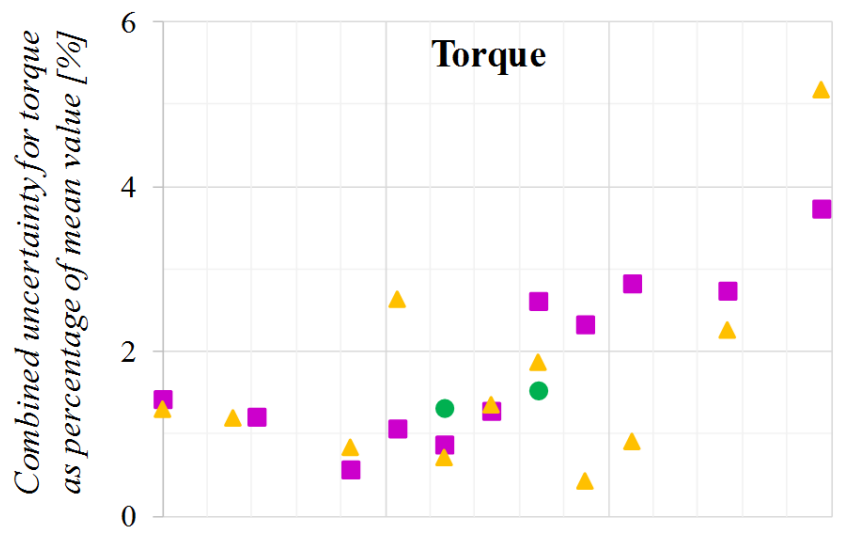

Figure 16. Cont. 


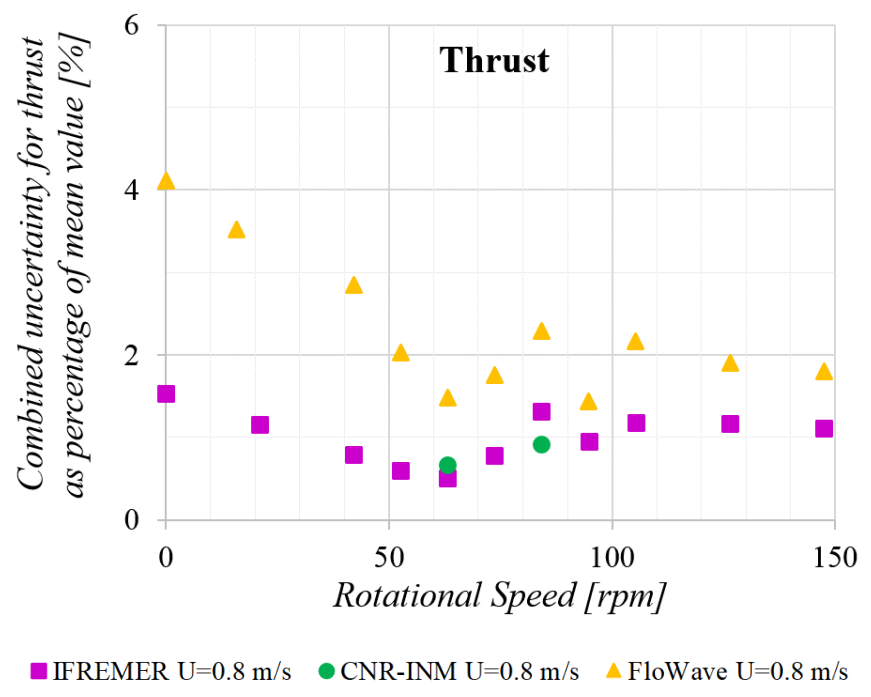

Figure 16. Combined uncertainty for all cases at $u=0.8 \mathrm{~m} / \mathrm{s}$ (i.e., cases 1, 2, 3 and 7) for torque (top) and thrust (bottom) as percentage of mean value based on the rotational speed for each the facilities.

This uncertainty analysis, although on some occasions incomplete, highlights the importance of repeating experiments, especially when these are performed in highly turbulent environments. Although flow characterisation repeat tests are not performed in these tests due to time constraints, they are recommended to further investigate uncertainty values which may be related to the facility rather than the device itself.

The tests performed in environments with zero turbulence levels (CNR-INM) do not reflect the real operating environment of a tidal turbine. Nevertheless, the comparison with results from facilities where turbulent flows can be generated is very useful to separate and analyse the effects of the testing environment on turbine performance characterisations.

\subsection{Turbine Stabilisation}

In an attempt to understand the high uncertainty values seen at FLOWAVE (Tables 10 and 11), Figures 17 and 18 look at how the turbine loading stabilises with time when operating at TSR $=4$ for cases 1 and 2 for thrust and torque, respectively. Images show repeat runs when available. These are calculated using the root-mean-square error (RMSE) over the time series (see Section 2.7).

At FLOWAVE, the thrust RMSE stabilises between 6 and $8 \mathrm{~N}$, whereas, at IFREMER, the thrust settles at values around $2 \mathrm{~N}$ except for the first few seconds of one case. At FLOWAVE, it takes the torque and thrust up to $50 \mathrm{~s}$ to stabilise, whereas this is obtained at around $20 \mathrm{~s}$ in IFREMER. From the present observations and previous observations done by [15], the turbulence intensity, the shear flow and the vertical flow component are higher at FLOWAVE than at IFREMER for case 1; thus, in the future, it would be advisable to acquire longer samples to allow the turbine to stabilise better in faster flow conditions.

The other case explored is wave case 2 . In contrast with the current-only cases, the time series seem to stabilise sooner at FloWAVE than at IFREMER. Again, relating this information to the flow characteristics, the turbulence intensity and wave heights obtained at IFREMER for this specific case are greater than at FLOWAVE. The addition of waves is responsible for the larger fluctuations around the average values seen at the beginning of the tests $(\sim 10 \mathrm{~s})$. 


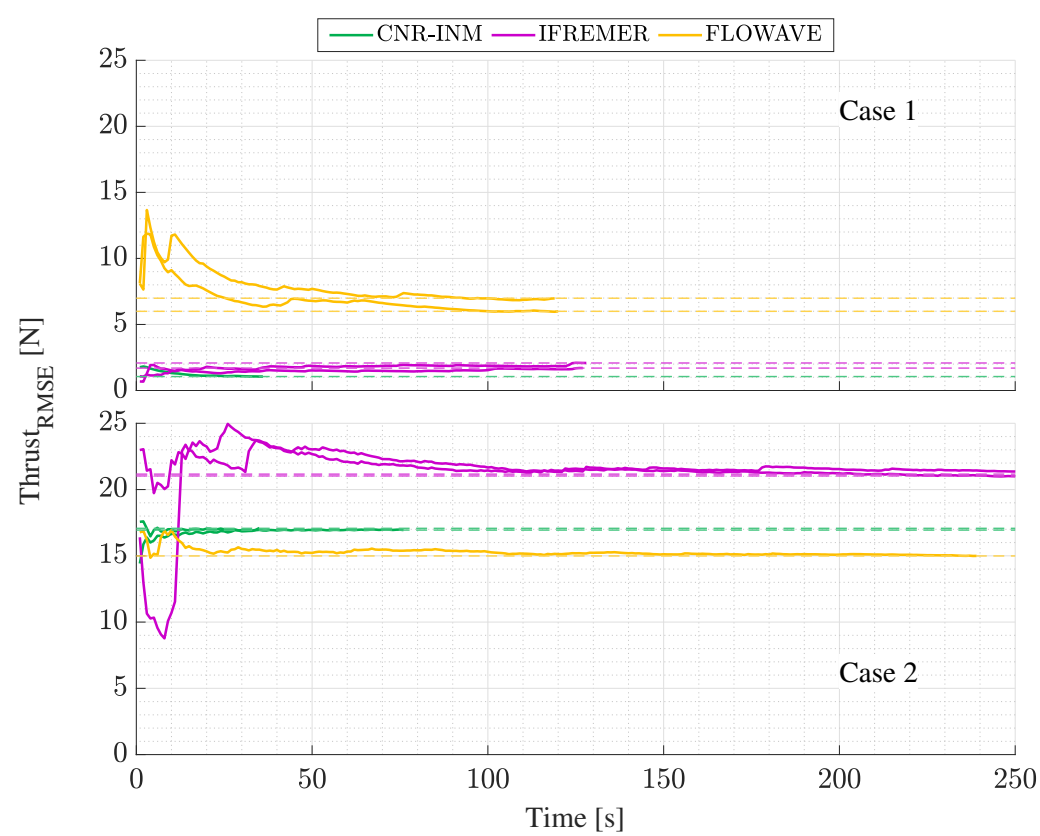

Figure 17. Stabilisation of the thrust RMSE at TSR $=4$ for case 1 (top) and 2 (bottom) at all facilities. Dashed lines are the RMSE value of the whole time series; same-colour curves are repeat tests when available.

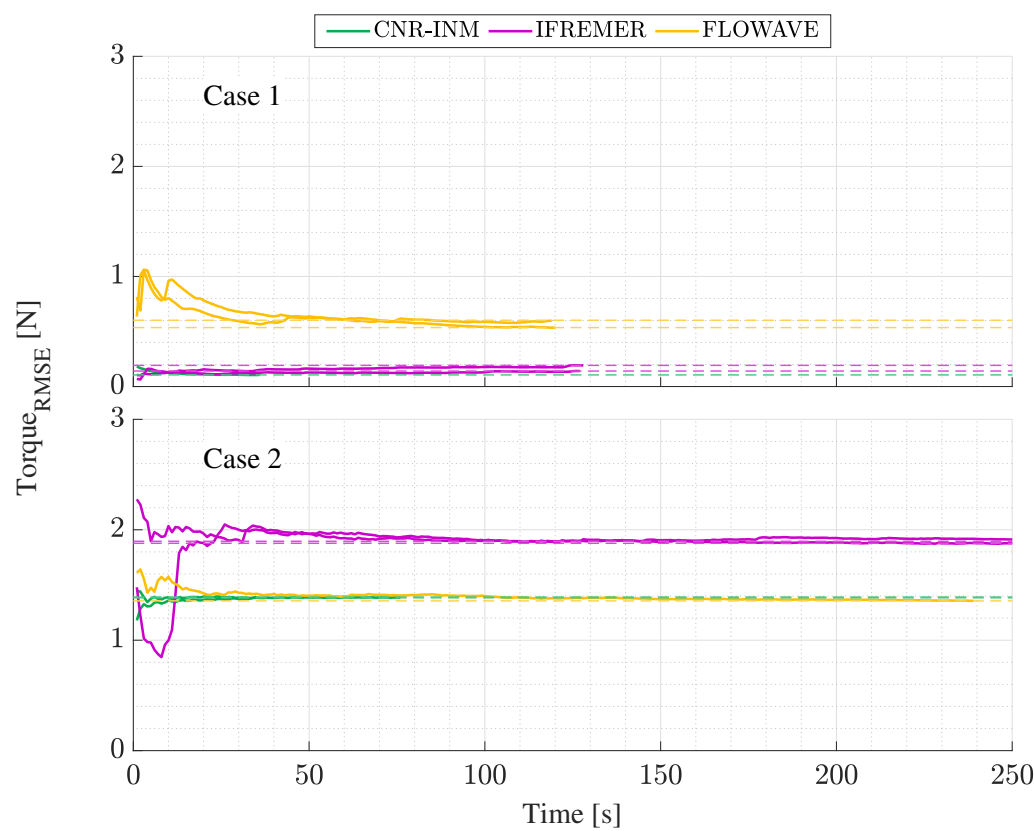

Figure 18. Stabilisation of the torque RMSE at TSR $=4$ for case 1 (top) and 2 (bottom) at all facilities. Dashed lines are the RMSE value of the whole time series; same-colour curves are repeat tests when available.

To understand the loading stabilisation, Figure 19 looks at the convergence of the flow velocity $u$ for case 1 at all facilities using the ADV mounted next to the rotor. At FLOWAVE and IFREMER, the turbine rotation has an influence on the flow velocity RMSE. As the rotational frequency of the turbine increases, the RMSE value decreases. In addition, RMSE values do not seem to stabilise throughout the length of the tests at FLOWAVE. At the lowest RPM, RMSE at FLOWAVE is more than three times the overall values at CNR-INM and IFREMER. 


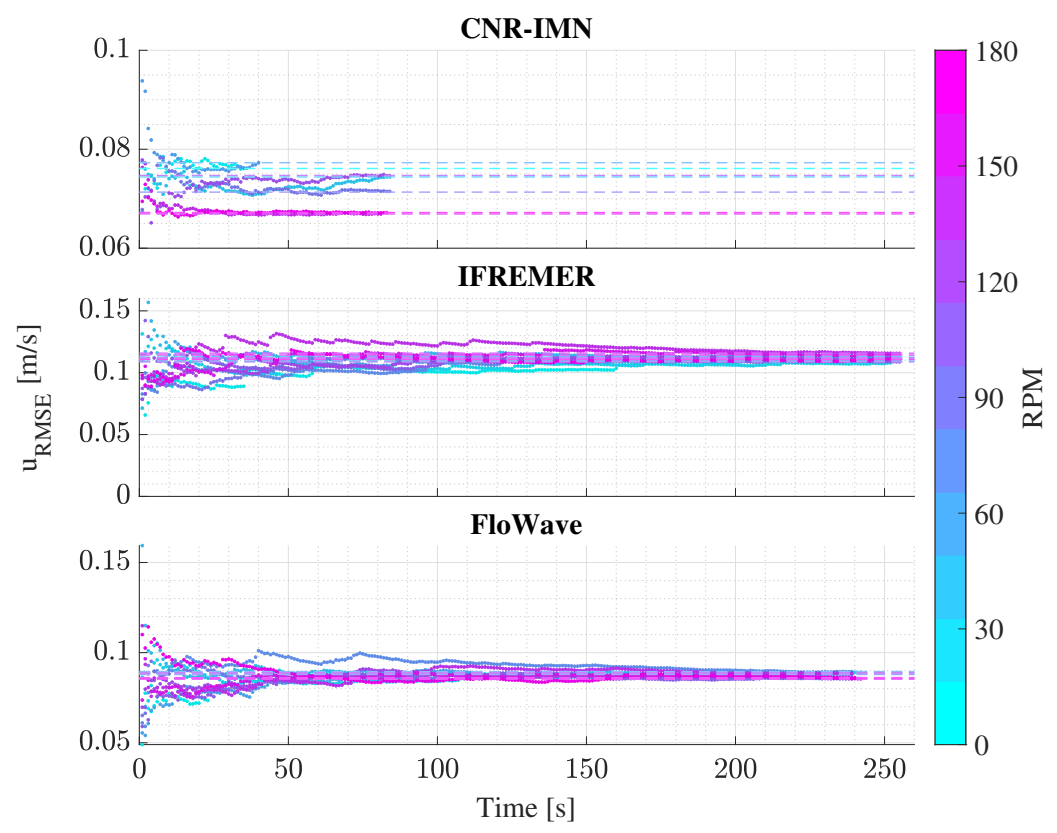

Figure 19. Stabilisation of the RMSE of $u$ for case 1 at all facilities.

\section{Conclusions, Recommendations and Perspectives}

This paper presents the results obtained from the first three trials done for the tidal MaRINET 2 Round Robin Test at the IFREMER, CNR-INM and FlOWAVE facilities. This Round Robin Test extends the previous program, i.e., keeping constant the turbine model and testing instruments, by incorporating waves and currents in the testing protocols.

As observed in the inflow velocity analysis, the hydrodynamic conditions are close between the three facilities. However, several differences appear, especially in terms of standard-deviation, mainly due to turbulence and wave-current interaction at the flume tanks. These differences are related to the intrinsic characteristics of the wave and current generation at all the facilities.

The synchronous measurements obtained with the ADV on the turbine side are influenced by the turbine's rotation. Flow velocities recorded with the ADV can be $8 \%$ higher than the upstream LDV measurements. This phenomenon is related to the acceleration of the flow as it bypasses the turbine. Consequently, the ADV velocity measurements on the side of the turbine cannot be used for normalising the performance coefficients or as reference values.

A number of wave probes are utilised during this Round Robin tests, highlighting the quality of different wave probe types to assess surface elevation, with the ultrasound and dynamic wave gauges showing a better performance. However, this wave gauges are only used at the tow tank facility. Work related to the use of these type of probes in turbulent flumes will be assessed in the future.

Depending on the facility, a larger amount of repeatability tests and longer acquisition times are advisable in order to reduce the uncertainty of the outcomes from the turbine loading and performance and improve the convergence of the time series. This is especially important when the data are used to verify numerical models. It is advisable to repeat flow characterisation procedures which may be influenced by the flow generation systems; e.g., overheating of pumps.

Due to the finite length of the towing tank at CNR-INM, the combinations of carriage speeds and wave periods allowed for an average of 20 wave periods per run. The achievable wave periods, however, have a high repeatability between them. Thus, deeming the quality of the data comparable to the data obtained at the other facilities.

Despite the work presented here, a deeper analysis is required. In the future, processing the blade forces and moments is envisioned. In addition, further tests are planned at 
the Kelvin Hydrodynamic Laboratory (KHL) towing tank at the University of Strathclyde and at the Queen's University Marine Laboratory (QML) tidal site. These coming RRTs will bring new wave-current flow conditions and certainly new interesting results.

Author Contributions: G.G., C.J., F.S., T.D. and B.G.S. conceptualised and formulated the hypothesis. B.G., S.O.-S. and R.M. conducted the formal analysis. B.G., G.G. and J.-V.F. provided the experimental turbine model and measurement tools. B.G., J.-V.F., F.S., I.S. and C.O. performed the investigation process and experiments. B.G., S.O.-S. and G.G. developed the methodology. B.G., S.O.-S., R.M. and G.G. wrote the original draft. F.S., I.S., T.D. and C.O. reviewed and revised the published work. All authors have read and agreed to the published version of the manuscript.

Funding: This work has received funding from the European Union's Horizon 2020 research and innovation programme under Grant No. 731084 (MaRINET2 project). This work is also partly financially supported by the European Union's European Regional Development Fund (ERDF), the French government, IFREMER and the region Hauts-de-France in the framework of the project CPER 2015-2020 MARCO.

Institutional Review Board Statement: Not applicable.

Informed Consent Statement: Not applicable.

Data Availability Statement: The corresponding raw data are available on the SEANOE platform [39].

Acknowledgments: The authors would like to thank Inès Belarbi and Thomas Bacchetti from IFREMER for their assistance in this experimental work.

Conflicts of Interest: The authors declare no conflict of interest. The funders had no role in the design of the study; in the collection, analyses, or interpretation of data; in the writing of the manuscript, or in the decision to publish the results.

\section{References}

1. Gaurier, B.; Germain, G.; Facq, J.V.; Johnstone, C.; Grant, A.; Day, A.; Nixon, E.; Di Felice, F.; Costanzo, M. Tidal energy “Round Robin" tests comparisons between towing tank and circulating tank results. Int. J. Mar. Energy 2015, 12, 87-109. [CrossRef]

2. Bahaj, A.; Molland, A.; Chaplin, J.; Batten, W. Power and thrust measurements of marine current turbines under various hydrodynamic flow conditions in a cavitation tunnel and a towing tank. Renew. Energy 2007, 32, 407-426. [CrossRef]

3. Murray, R.E.; Ordonez-Sanchez, S.; Porter, K.E.; Doman, D.A.; Pegg, M.J.; Johnstone, C.M. Towing Tank and Flume Testing of Passively Adaptive Composite Tidal Turbine Blades. In Proceedings of the 12th European Wave and Tidal Energy Conference, Cork, Ireland, 27 August-1 September 2017.

4. Allmark, M.; Ellis, R.; Lloyd, C.; Ordonez-Sanchez, S.; Johannesen, K.; Byrne, C.; Johnstone, C.; O’Doherty, T.; Mason-Jones, A. The development, design and characterisation of a scale model Horizontal Axis Tidal Turbine for dynamic load quantification. Renew. Energy 2020, 156, 913-930. [CrossRef]

5. Barltrop, N.; Varyani, K.S.; Grant, A.; Clelland, D.; Pham, X. Investigation into wave-current interactions in marine current turbines. Proc. Inst. Mech. Eng. Part A J. Power Energy 2007, 221, 233-242. [CrossRef]

6. Gaurier, B.; Davies, P.; Deuff, A.; Germain, G. Flume tank characterization of marine current turbine blade behaviour under current and wave loading. Renew. Energy 2013, 59, 1-12. [CrossRef]

7. Galloway, P.W.; Myers, L.E.; Bahaj, A.S. Quantifying wave and yaw effects on a scale tidal stream turbine. Renew. Energy 2014, 63, 297-307. [CrossRef]

8. de Jesus Henriques, T.A.; Tedds, S.C.; Botsari, A.; Najafian, G.; Hedges, T.S.; Sutcliffe, C.J.; Owen, I.; Poole, R.J. The effects of wave-current interaction on the performance of a model horizontal axis tidal turbine. Int. J. Mar. Energy 2014, 8, 17-35. [CrossRef]

9. Martinez, R.; Payne, G.S.; Bruce, T. The effects of oblique waves and currents on the loadings and performance of tidal turbines. Ocean Eng. 2018, 164, 55-64. [CrossRef]

10. Ordonez-Sanchez, S.; Allmark, M.; Porter, K.; Ellis, R.; Lloyd, C.; Santic, I.; O’Doherty, T.; Johnstone, C. Analysis of a HorizontalAxis Tidal Turbine Performance in the Presence of Regular and Irregular Waves Using Two Control Strategies. Energies 2019, 12, 367. [CrossRef]

11. Draycott, S.; Payne, G.; Steynor, J.; Nambiar, A.; Sellar, B.; Venugopal, V. An experimental investigation into nonlinear wave loading on horizontal axis tidal turbines. J. Fluids Struct. 2019, 84, 199-217. [CrossRef]

12. Draycott, S.; Nambiar, A.; Sellar, B.; Davey, T.; Venugopal, V. Assessing extreme loads on a tidal turbine using focused wave groups in energetic currents. Renew. Energy 2019, 135, 1013-1024. [CrossRef]

13. Porter, K.; Ordonez-Sanchez, S.; Murray, R.E.; Allmark, M.; Johnstone, C.M.; O’Doherty, T.; Mason-Jones, A.; Doman, D.A.; Pegg, M.J. Flume Testing of Passively Adaptive Composite Tidal Turbine Blades under Combined Wave and Current Loading. J. Fluids Struct. 2020, 93. [CrossRef] 
14. Martinez, R.; Ordonez-Sanchez, S.; Allmark, M.; Lloyd, C.; O’Doherty, T.; Germain, G.; Gaurier, B.; Johnstone, C. Analysis of the effects of control strategies and wave climates on the loading and performance of a laboratory scale horizontal axis tidal turbine. Ocean Eng. 2020, 212, 107713. [CrossRef]

15. Gaurier, B.; Ordonez-Sanchez, S.; Facq, J.V.; Germain, G.; Johnstone, C.; Martinez, R.; Salvatore, F.; Santic, I.; Davey, T.; Old, C.; et al. MaRINET2 Tidal Energy Round Robin Tests-Performance Comparison of a Horizontal Axis Turbine Subjected to Combined Wave and Current Conditions. J. Mar. Sci. Eng. 2020, 8, 463. [CrossRef]

16. EquiMar. Protocols for the Equitable Assessment of Marine Energy Converters; Technical Report 213380; The Institute for Energy Systems, The University of Edinburgh: Edinburgh, UK, 2011.

17. Specialist Committee on Testing of Marine Renewable Devices. Recommended Procedures and Guidelines—Model Tests for Current Turbines; Technical Report; ITTC Association, Zürich, Switzerland, 2017.

18. Day, A.H.; Babarit, A.; Fontaine, A.A.; He, Y.P.; Kraskowski, M.; Murai, M.; Penesis, I.; Salvatore, F.; Shin, H.K. Hydrodynamic modelling of marine renewable energy devices: A state of the art review. Ocean Eng. 2015, 108, 46-69. [CrossRef]

19. Gaurier, B.; Germain, G.; Facq, J.V.; Bacchetti, T. Wave and Current Flume Tank of Boulogne-Sur-Mer. Description of the Facility and Its Equipment; Technical Report 19CSMBL18; IFREMER, Brest, France, 2018. [CrossRef]

20. Consiglio Nazionale delle Ricerche. Available online: http://www.inm.cnr.it/labs/emilio-castagneto-seakeeping-tank/ (accessed on 3 March 2021).

21. Sutherland, D.R.; Noble, D.R.; Steynor, J.; Davey, T.; Bruce, T. Characterisation of current and turbulence in the FloWave Ocean Energy Research Facility. Ocean Eng. 2017, 139, 103-115. [CrossRef]

22. SIXAXES. Available online: http:/ / www.sixaxes.com/ (accessed on 3 March 2021).

23. Nortek Group. The Comprehensive Manual for Velocimeters. Nortek Group: Rud, Norway, 2018.

24. Goring, D.G.; Nikora, V.I. Despiking Acoustic Doppler Velocimeter Data. J. Hydraul. Eng. 2002, 128, 117-126. [CrossRef]

25. Gaurier, B.; Germain, G.; Pinon, G. How to correctly measure turbulent upstream flow for marine current turbine performance evaluation? In Proceedings of the 3rd International Conference on Renewable Energies Offshore, Lisbon, Portugal, 8-10 October 2018.

26. Lloyd, C.; Allmark, M.; Ordonez-Sanchez, S.; Martinez, R.; Johnstone, C.; Germain, G.; Gaurier, B.; Mason-Jones, A.; O’Doherty, T. Validation of the dynamic load characteristics on a Tidal Stream Turbine when subjected to wave and current interaction. Ocean Eng. 2021, 222, 108360. [CrossRef]

27. Dante Dynamics. Available online: https://www.dantecdynamics.com/solutions-applications/solutions/fluid-mechanics/ laser-doppler-anemometry-lda/flowexplorer/ (accessed on 3 March 2021).

28. Sellar, B.; Wakelam, G. Characterisation of tidal flows at the European Marine Energy Centre in the absence of ocean waves. Energies 2018, 11, 176. [CrossRef]

29. Goddijn-Murphy, L.; Woolf, D.K.; Easton, M.C. Current patterns in the inner sound (Pentland Firth) from underway ADCP data. J. Atmos. Ocean. Technol. 2013, 30, 96-111. [CrossRef]

30. Evans, P.S. Hydrodynamic Characteristics of Macrotidal Straits and Implications for Tidal Stream Turbine Deployment. Ph.D. Thesis, Cardiff University, Cardiff, Wales, 2014.

31. Easton, M.C. An Assessment of Tidal Energy and the Environmental Response to Extraction at a Site in the Pentland Firth. Ph.D. Thesis, University of Aberdeen, Aberdeen, Scotland, 2013.

32. Munk, W.H. Origin and generation of waves. In Proceedings of the 1st Conference on Coastal Engineering, Long Beach, CA, USA, 1 January 1950; pp. 1-4.

33. Blackmore, T.; Myers, L.E.; Bahaj, A.S. Effects of turbulence on tidal turbines: Implications to performance, blade loads, and condition monitoring. Int. J. Mar. Energy 2016, 14, 1-26. [CrossRef]

34. Bell, S. Good Practice Guide No. 11-The Beginner's Guide to Guide to Uncertainty of Measurement; Technical Report 2; National Physical Laboratory: Teddington, UK, 2001.

35. Specialist Committee on Testing of Marine Renewable Devices. Recommended Procedures and Guidelines; Uncertainty AnalysisExample for Horizontal Axis Turbines; Technical Report; ITTC Association, Zürich, Switzerland, 2017.

36. Hyndman, R.J.; Koehler, A.B. Another look at measures of forecast accuracy. Int. J. Forecast. 2006, 22, 679-688. [CrossRef]

37. Draycott, S.; Sutherland, D.R.J.; Steynor, J.; Sellar, B.G.; Venugopal, V. Re-creating waves in large currents for tidal energy applications. Energies 2017, 10, 1838. [CrossRef]

38. Murray, R.E.; Ordonez-Sanchez, S.; Porter, K.E.; Doman, D.A.; Pegg, M.J.; Johnstone, C.M. Towing Tank Testing of Passively Adaptive Composite Tidal Turbine Blades and Comparison to Design Tool. Renew. Energy 2018, 116, 202-214. [CrossRef]

39. Gaurier, B.; Ordonez-Sanchez, S.; Germain, G.; Facq, J.V.; Johnstone, C.; Salvatore, F.; Santic, I. MaRINET2 Tidal "Round Robin" Dataset: Comparisons between Towing and Circulating Tanks Test Results for a Tidal Energy Converter Submitted to Wave and Current Interactions; SEANOE, Brest, France, 2018. [CrossRef] 